\title{
Antenna Technologies for Future NASA Exploration Missions
}

NASA's plans for the manned exploration of the moon and Mars will rely heavily on the development of a reliable communications infrastructure on the surface and back to Earth. Future missions will thus focus not only on gathering scientific data, but also on the formation of the communications network. In either case, unique requirements become imposed on the antenna technologies necessary to accomplish these tasks. For example, surface activity applications such as robotic rovers, human extravehicular activities (EVA), and probes will require small size, lightweight, low power, multi-functionality, and robustness for the antenna elements being considered. Trunk-line communications to a centralized habitat on the surface and back to Earth (e.g., surface relays, satellites, landers) will necessitate wide-area coverage, high gain, low mass, deployable antennas. Likewise, the plethora of low to high data rate services desired to guarantee the safety and quality of mission data for robotic and human exploration will place additional demands on the technology.

Over the past year, NASA Glenn Research Center has been heavily involved in the development of candidate antenna technologies with the potential for meeting these strict requirements. This technology ranges from electrically small antennas to phased array and large inflatable structures. A summary of this overall effort is provided, with particular attention being paid to small antenna designs and applications. A discussion of the Agency-wide activities of the Exploration Systems Mission Directorate (ESMD) in forthcoming NASA missions, as they pertain to the communications architecture for the lunar and Martian networks is performed, with an emphasis on the desirable qualities of potential antenna element designs for envisioned communications assets. Identified frequency allocations for the lunar and Martian surfaces, as well as assetspecific data services will be described to develop a foundation for viable antenna technologies which might address these requirements and help guide future technology development decisions. 


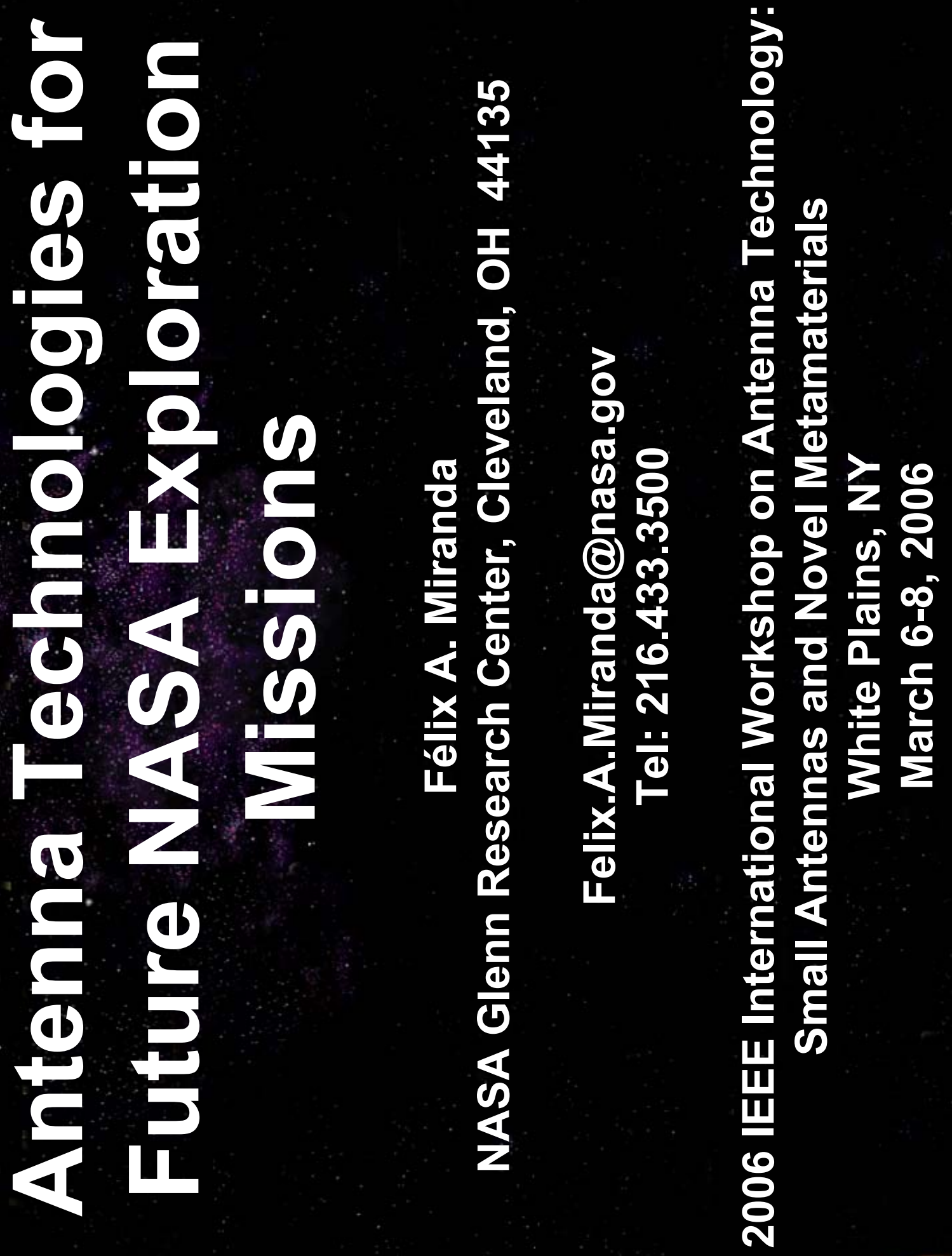




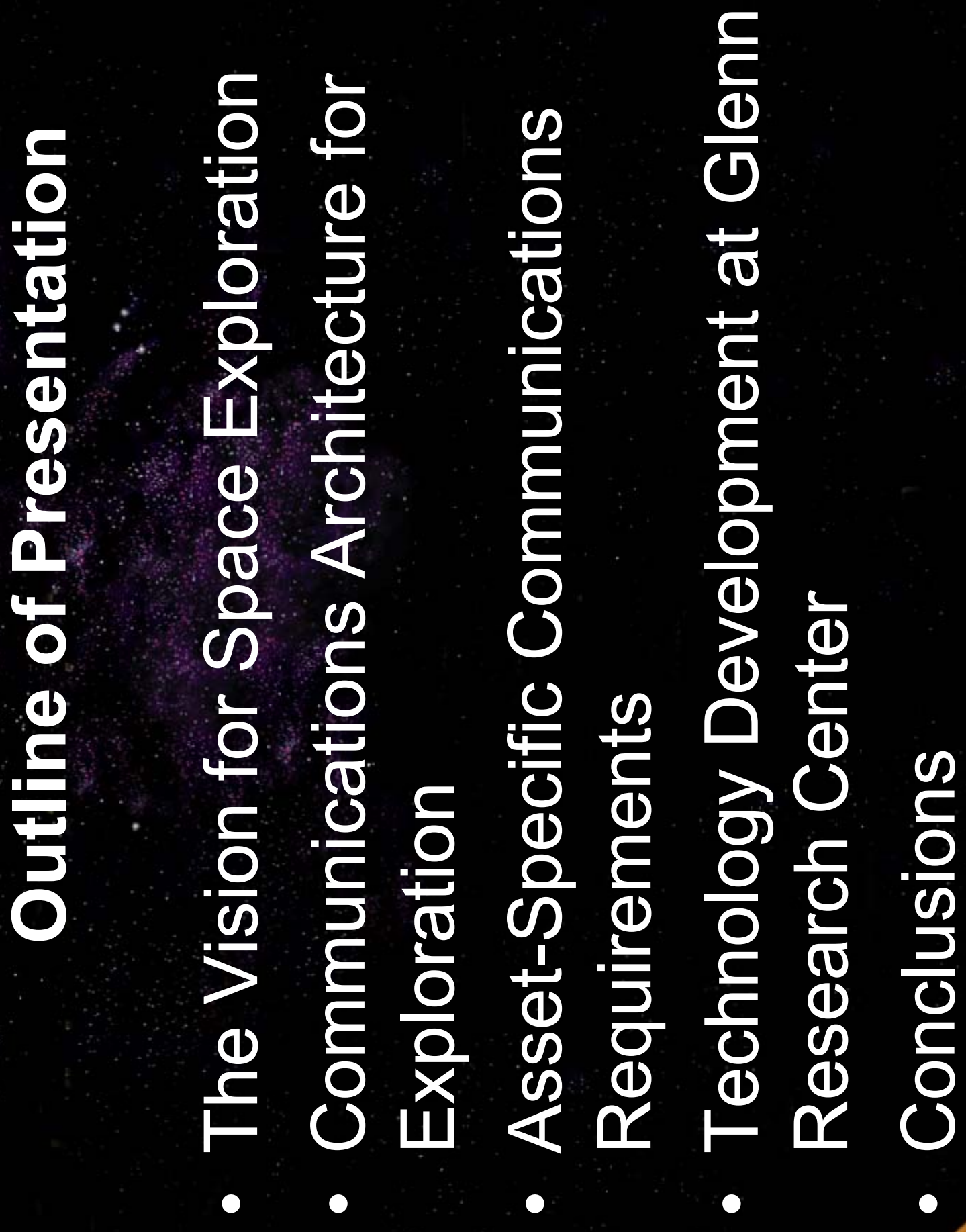




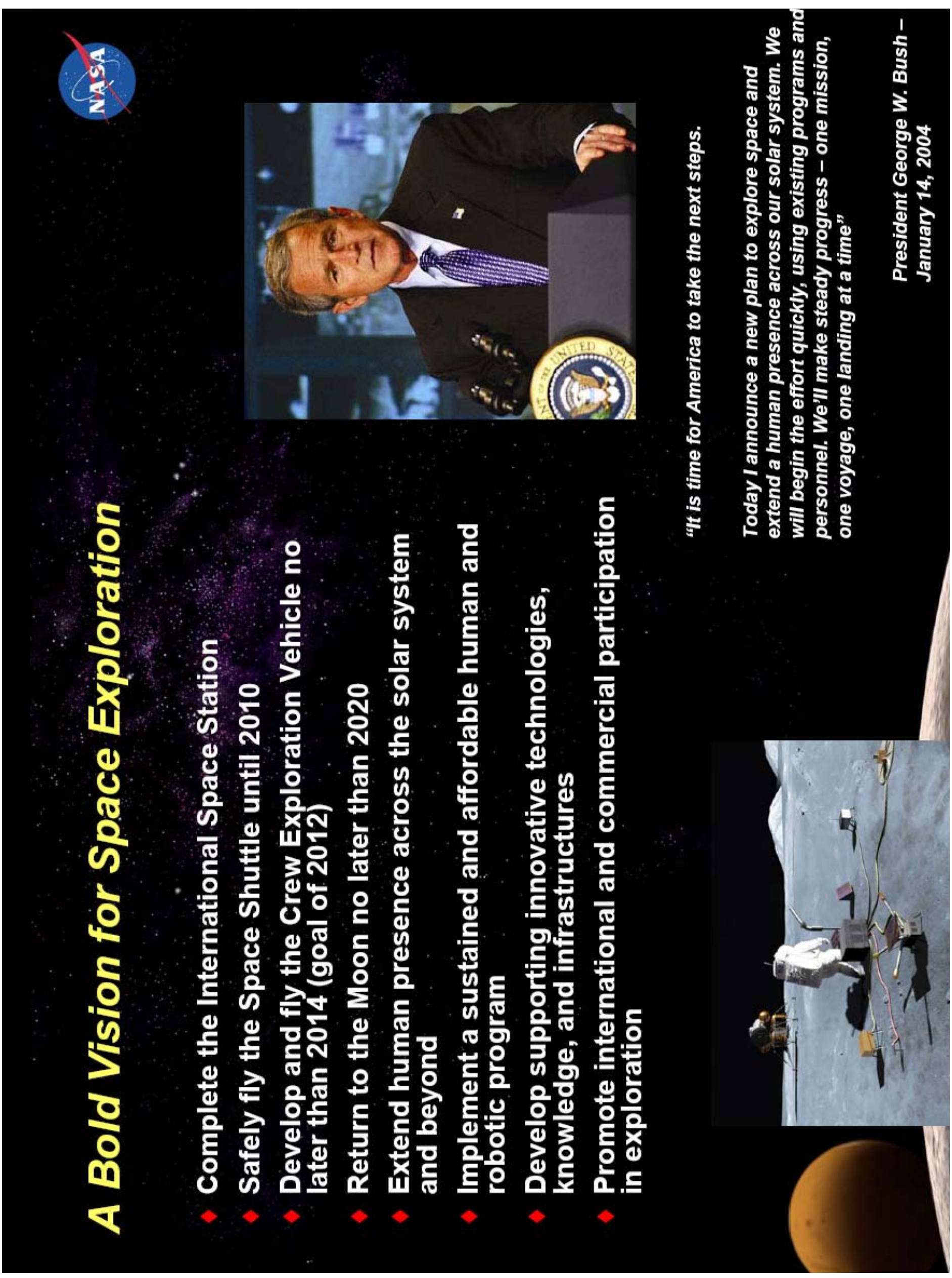




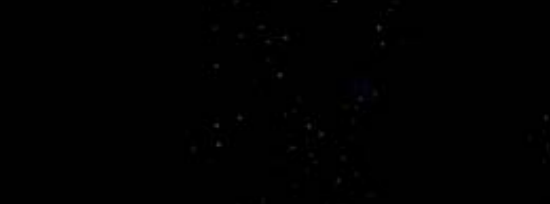

(1)

(4)

E

0

4

0

0

몬

(10

0

$\sigma$

5

E

3 
$\varepsilon$

के

(1)든음

\pm 응 중

ब은

ळ 든

C

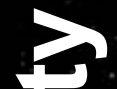

(2) 0

ㄹ. $\frac{0}{0}$

(D) 0

$\times \quad 0$

II

40

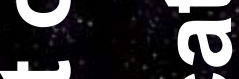

ㄹ. 0

(5)

ह 5

0

(b)

(1)

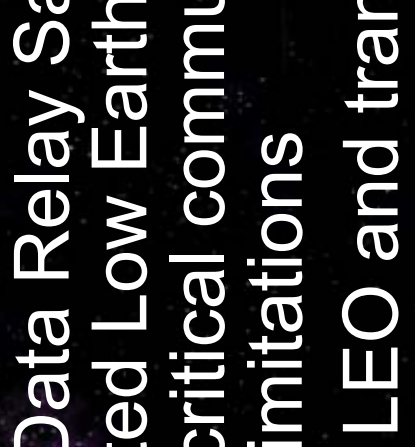

$\frac{t}{0}$

$\frac{\varepsilon}{0} \frac{\frac{1}{c}}{\frac{1}{2}}$

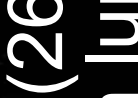

पे

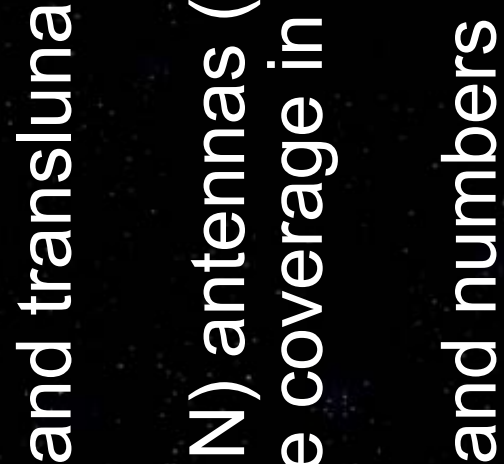

-

른

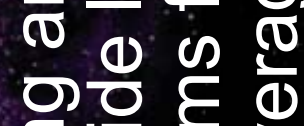

(1)

क

क

닌

(1)

는응 힝

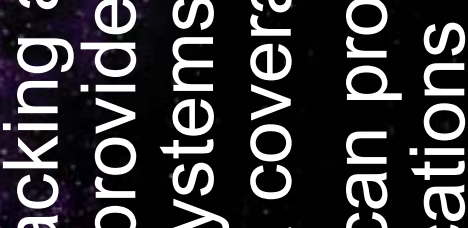

즌 응 क

(1)

앙 응 은

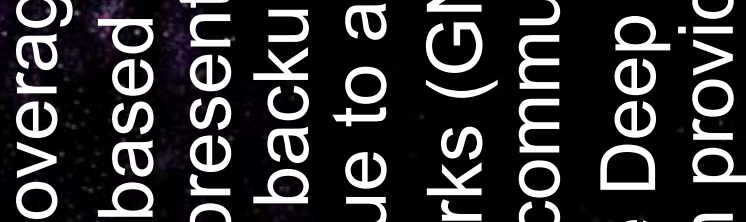

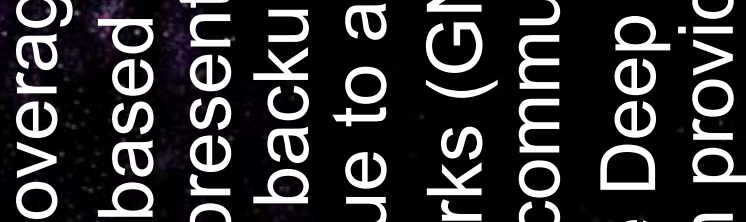

일흔응 흥

zํㅗㄱ

क웡

ఏ $\frac{\mathrm{C}}{\bar{C}}$

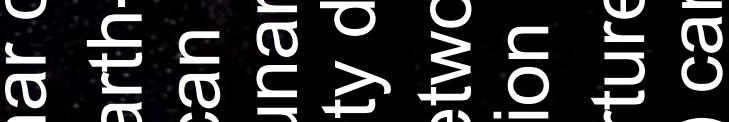

듕

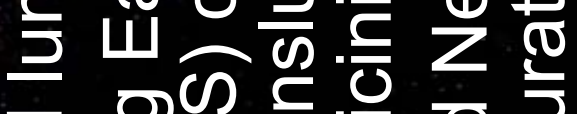

얻) 듕 은 응

$\Phi$ 든

등

$\frac{1}{10} \frac{\varepsilon}{\circ}$

क人 $>07$

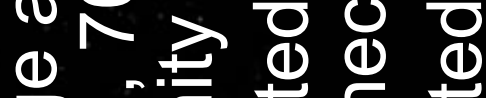

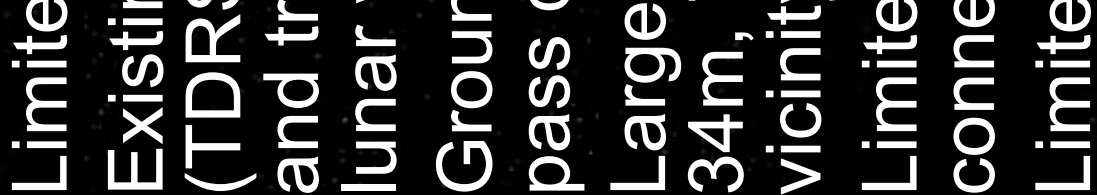




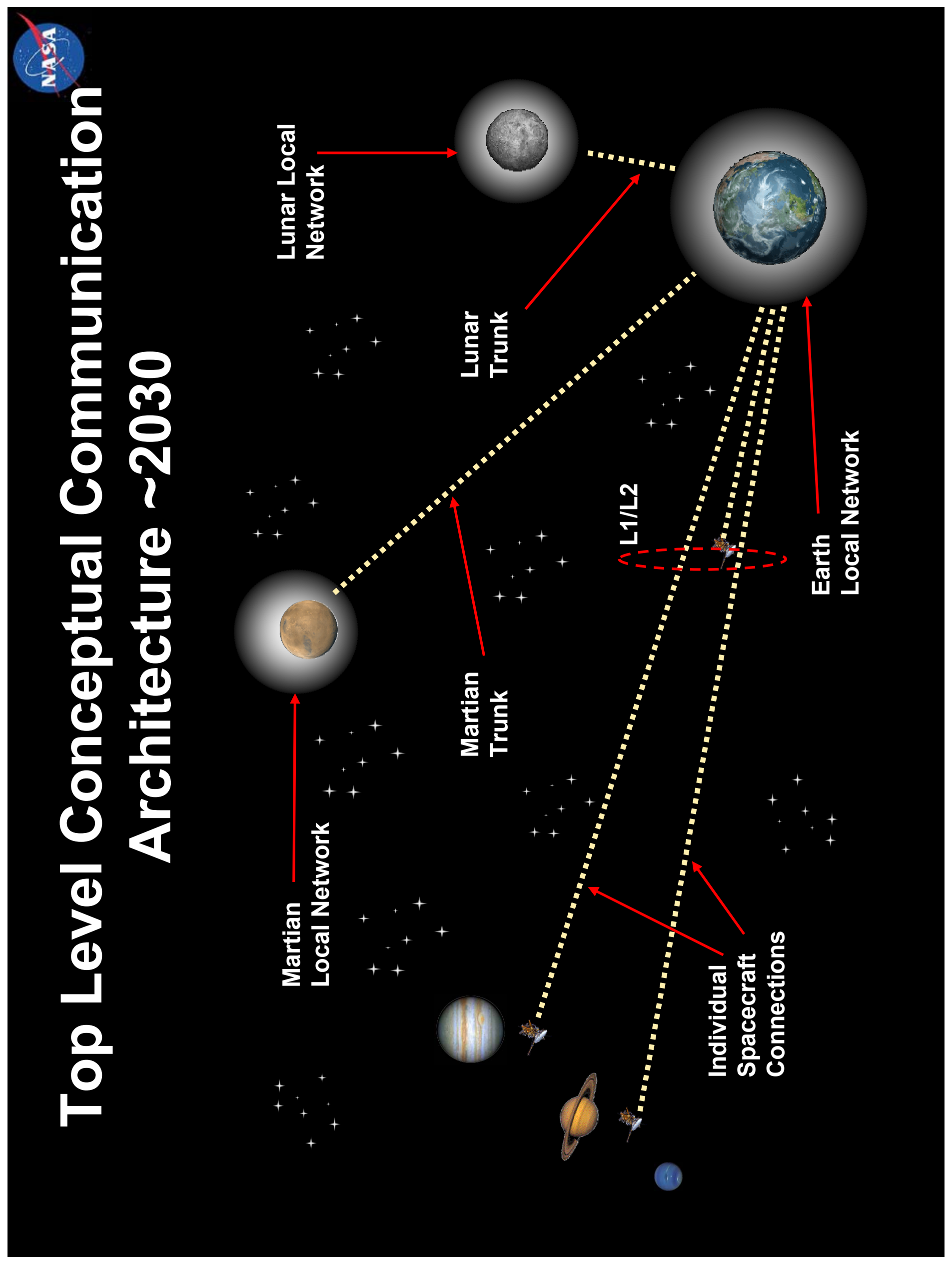




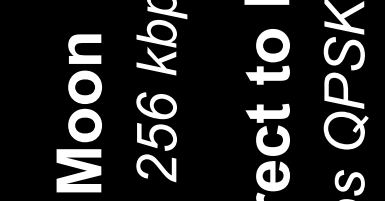

(a)

0

0

4

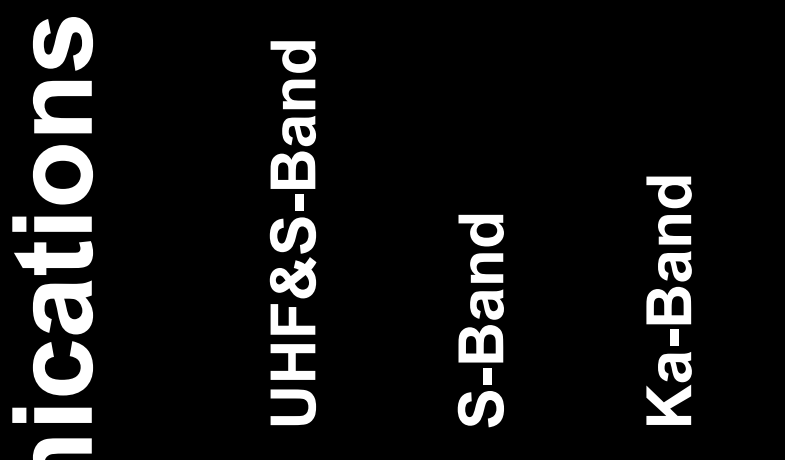

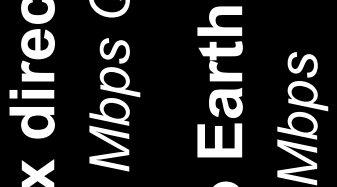

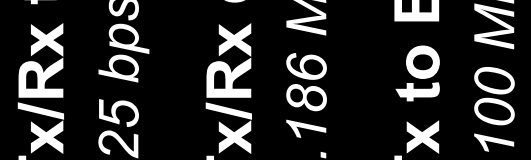

$x N \underset{N}{N} N \frac{\pi}{\Lambda}$ $\frac{25}{20}$

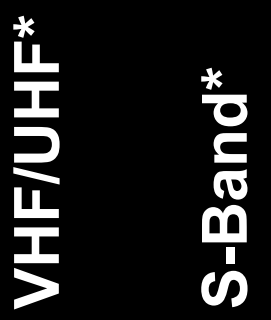

है仓

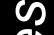

$\frac{1}{0}$

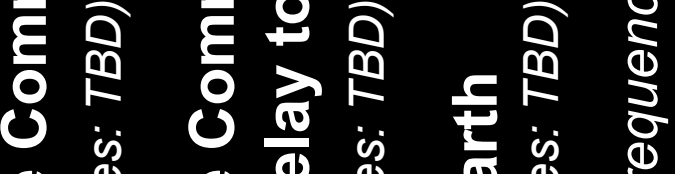

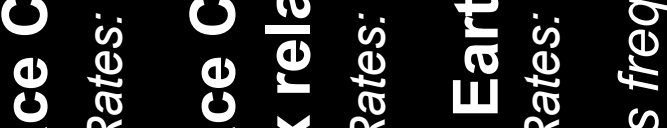

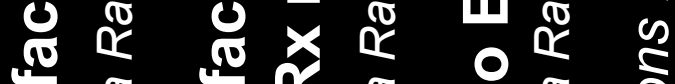

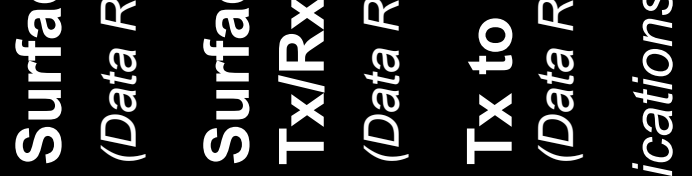

$\frac{\xi}{\frac{\delta}{\delta}}$

$\frac{1}{2}$

8

?

a

3
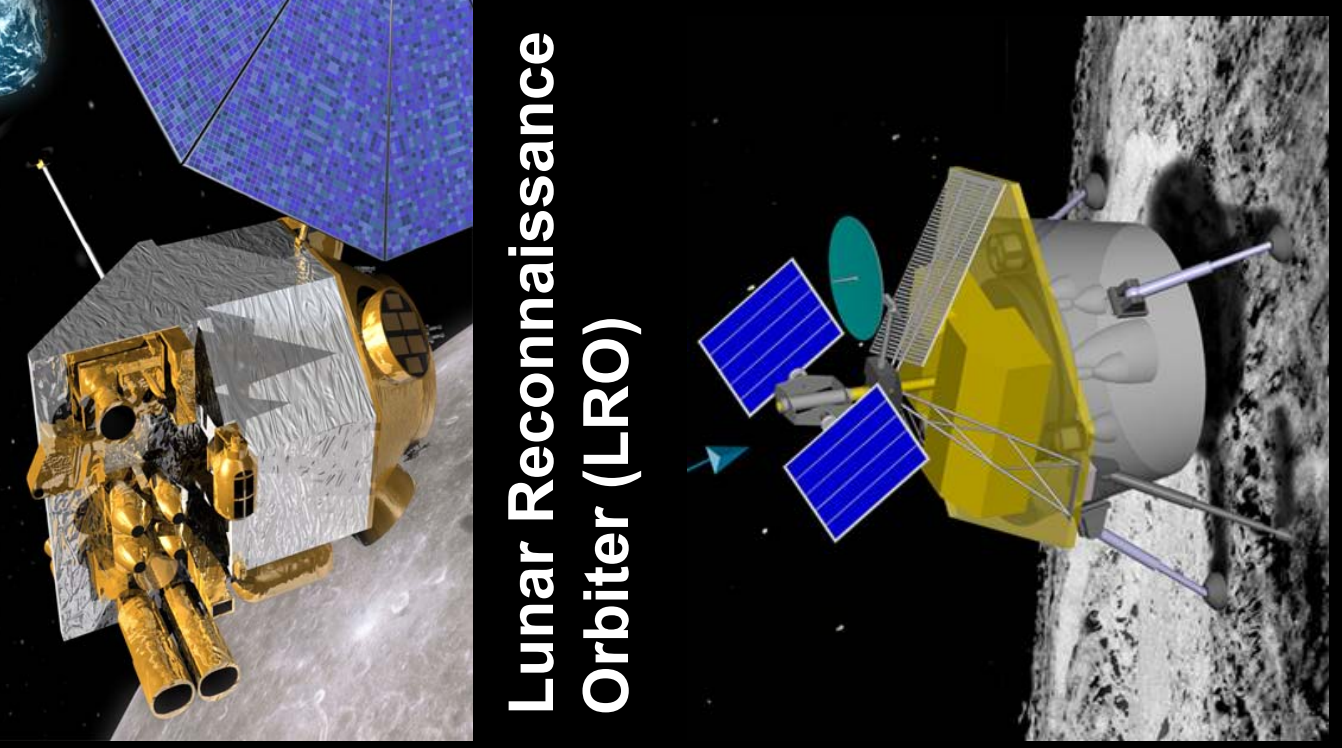


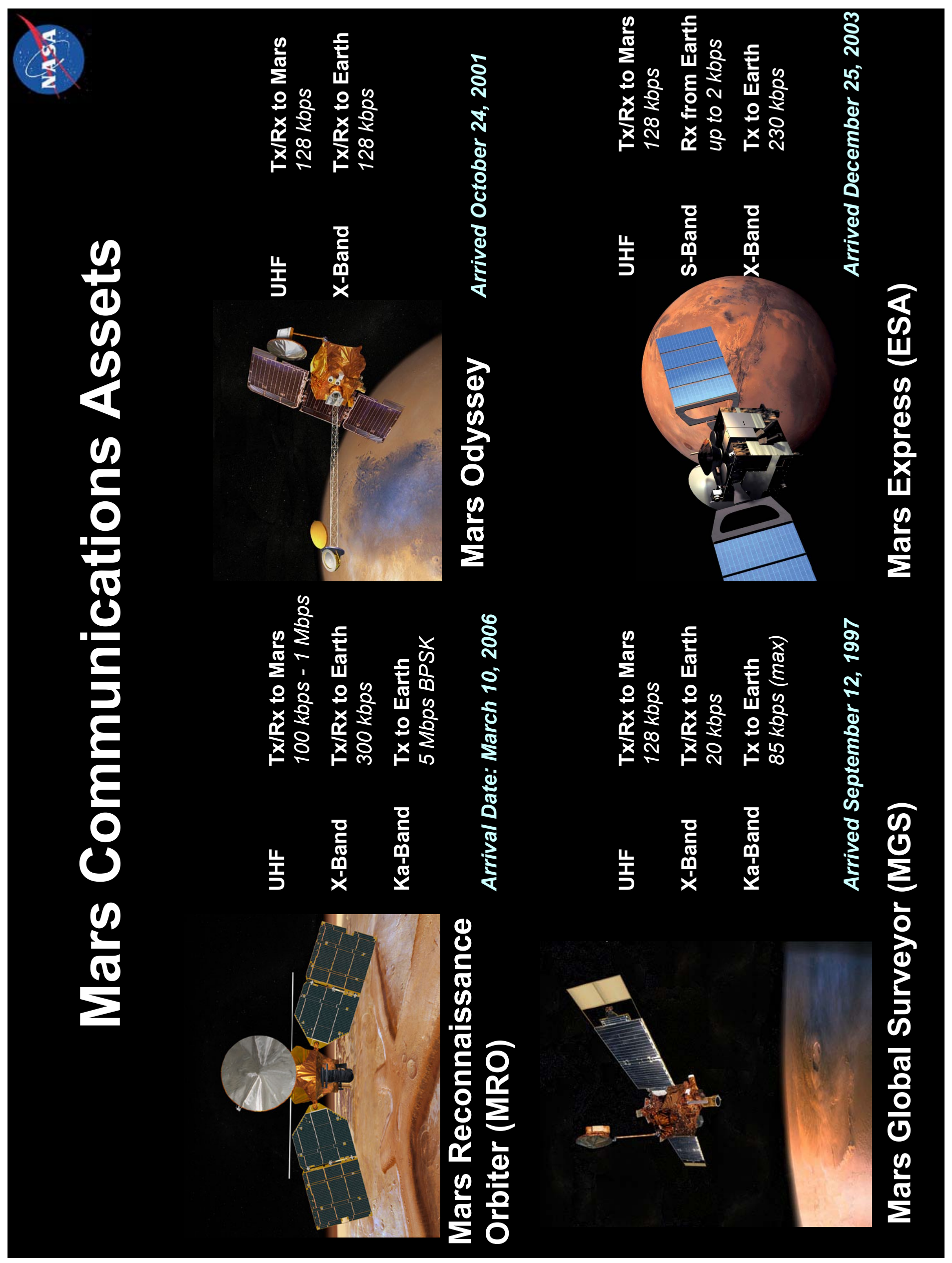




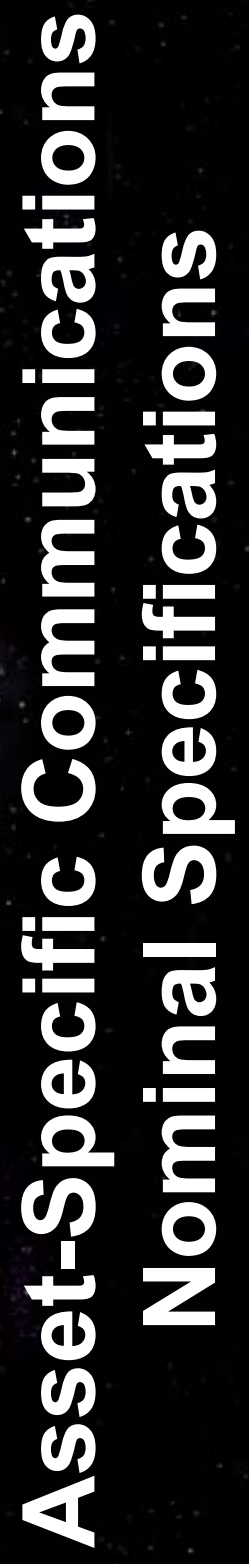




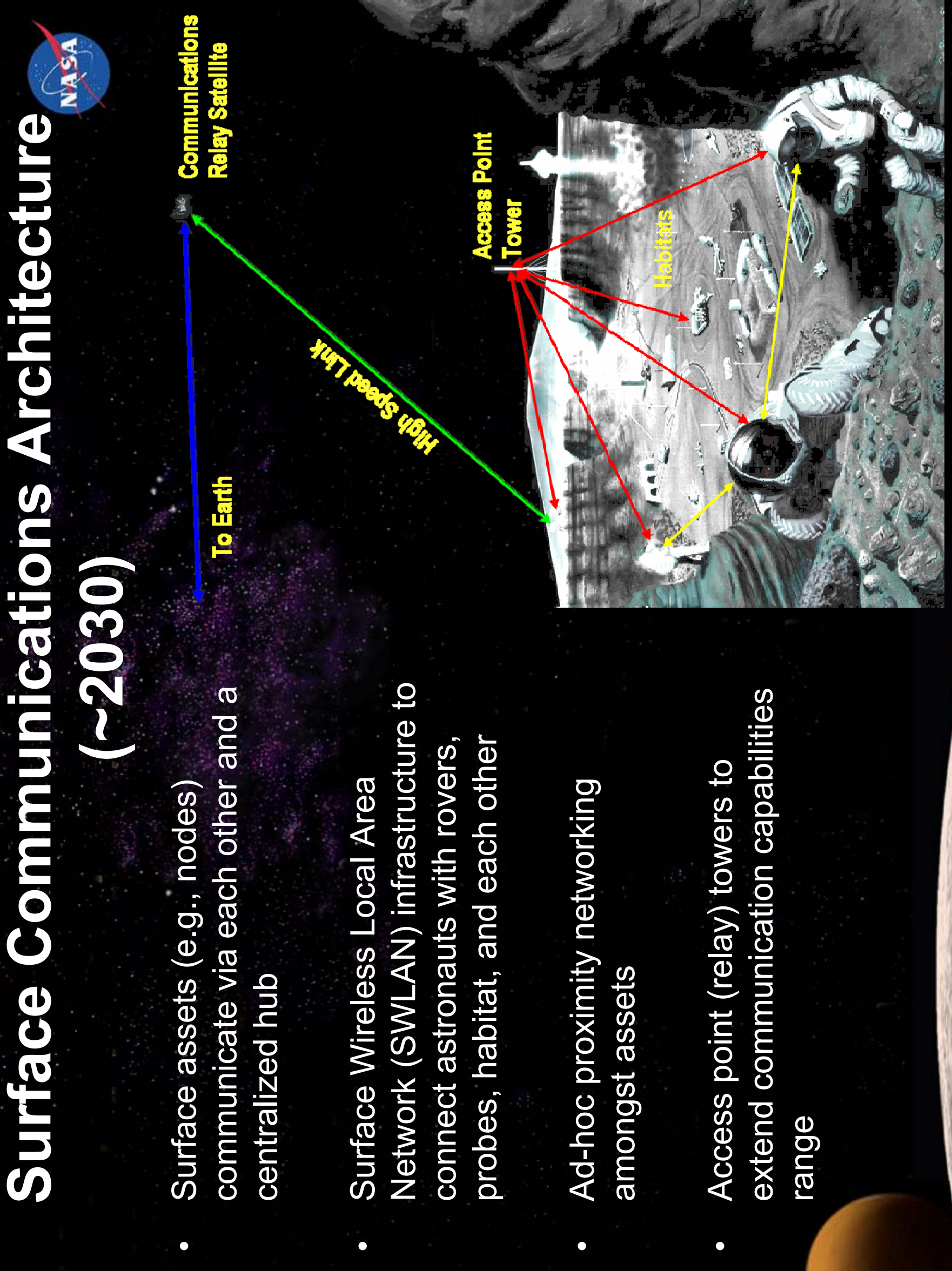




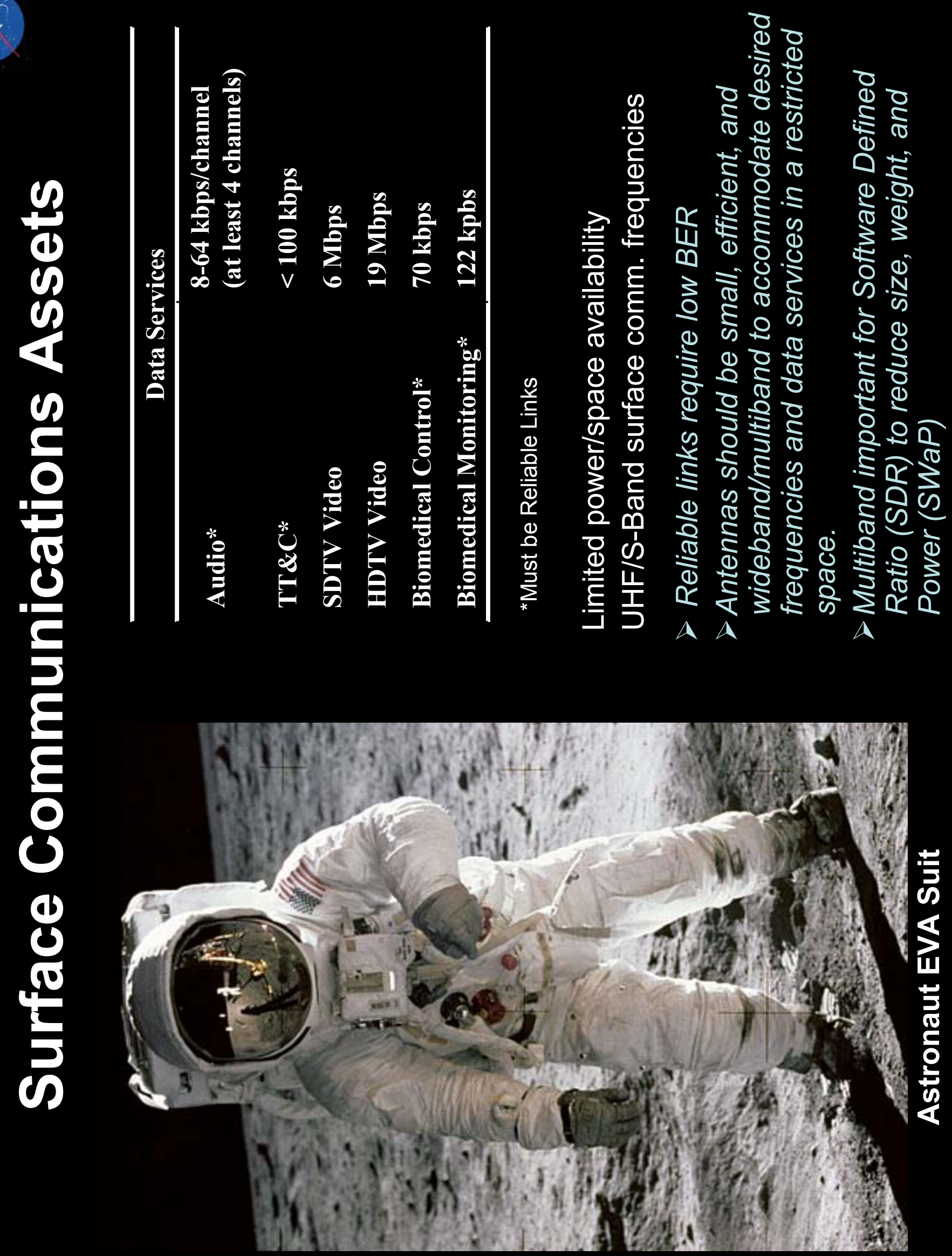



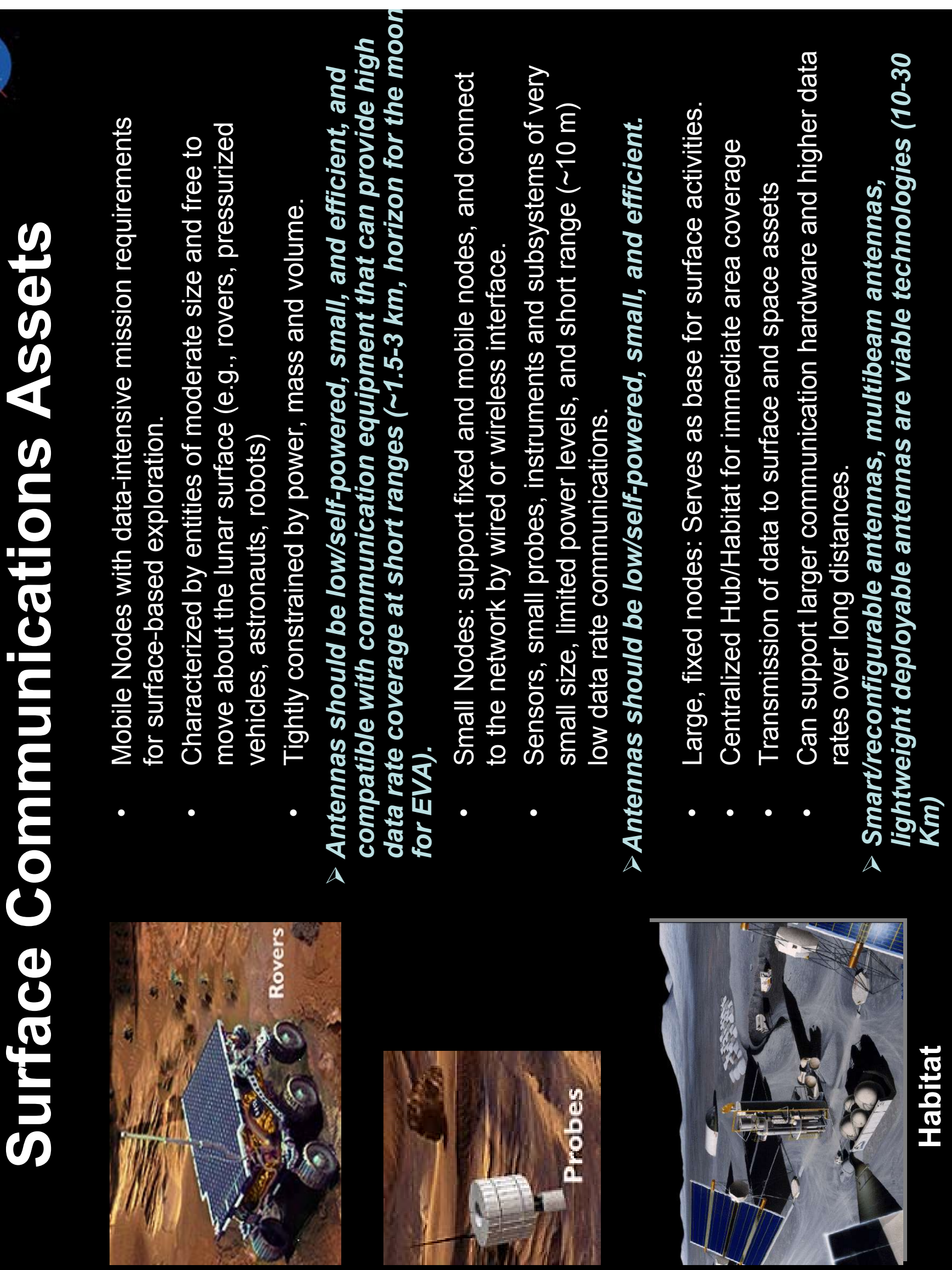


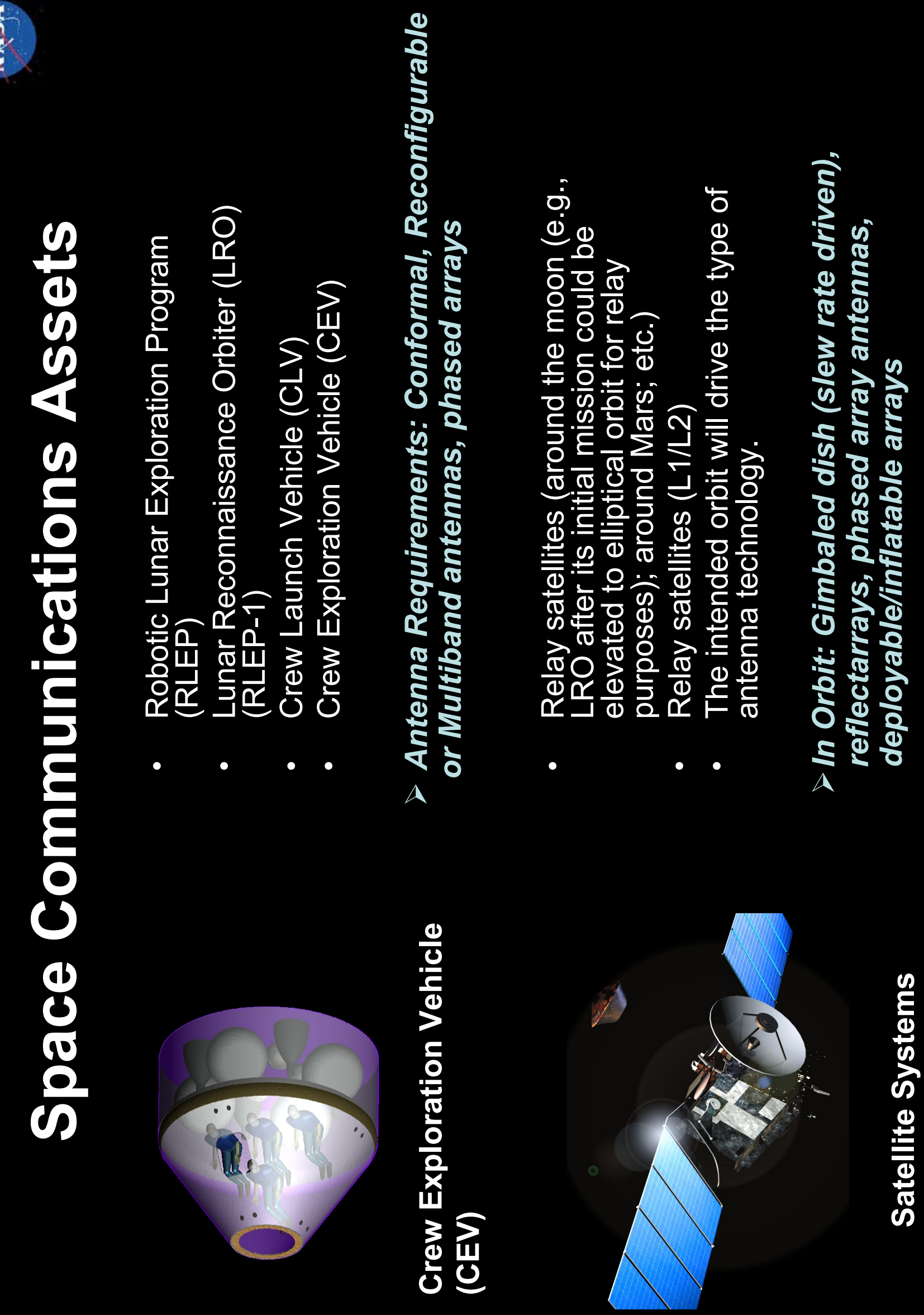




\begin{tabular}{|c|c|c|c|c|}
\hline $\begin{array}{l}\frac{9}{0} \\
\frac{0}{8} \\
\frac{0}{0} \\
\frac{0}{2} \\
\frac{0}{0} \\
\frac{0}{0} \\
\frac{\pi}{0} \\
\frac{0}{0} \\
\frac{5}{4} \\
\frac{0}{0} \\
\frac{0}{0} \\
0\end{array}$ & 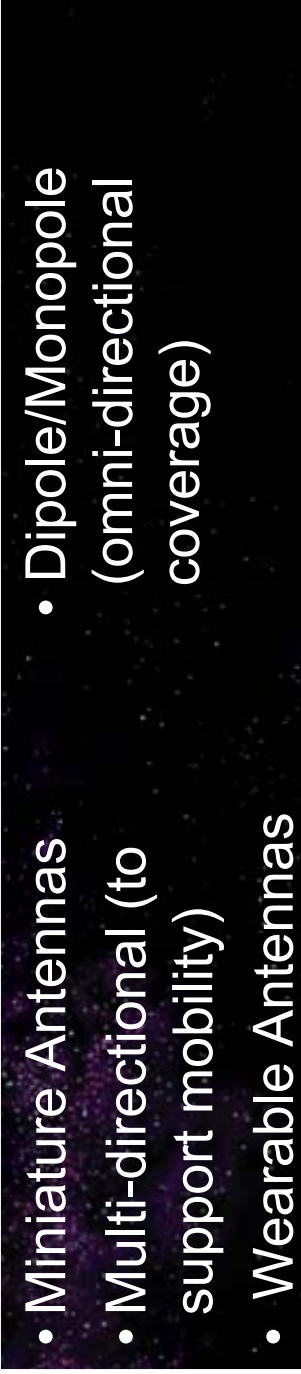 & 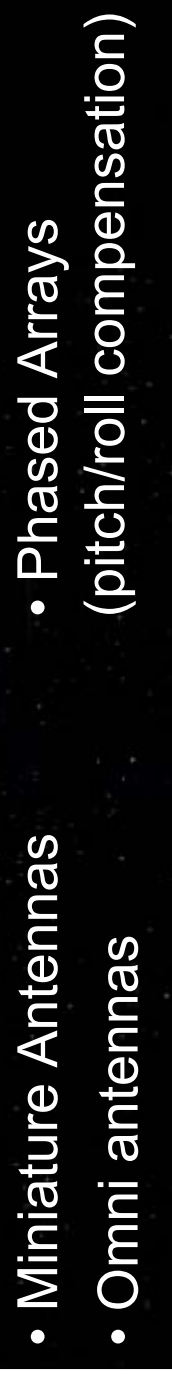 & 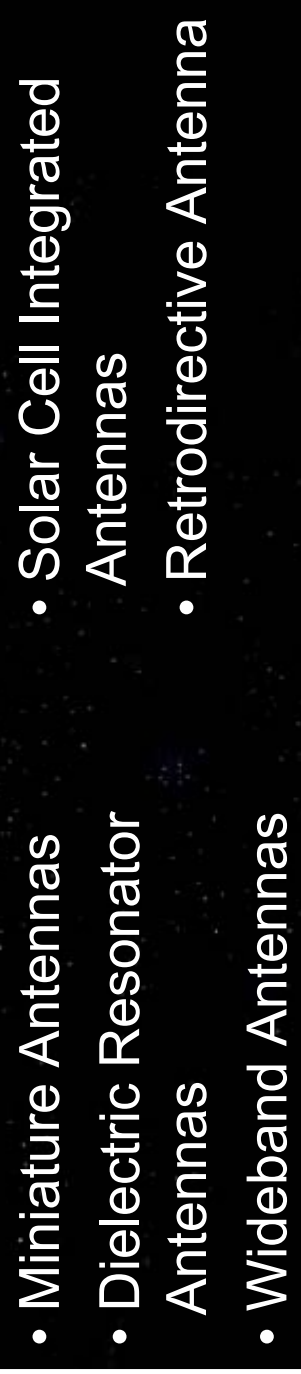 & 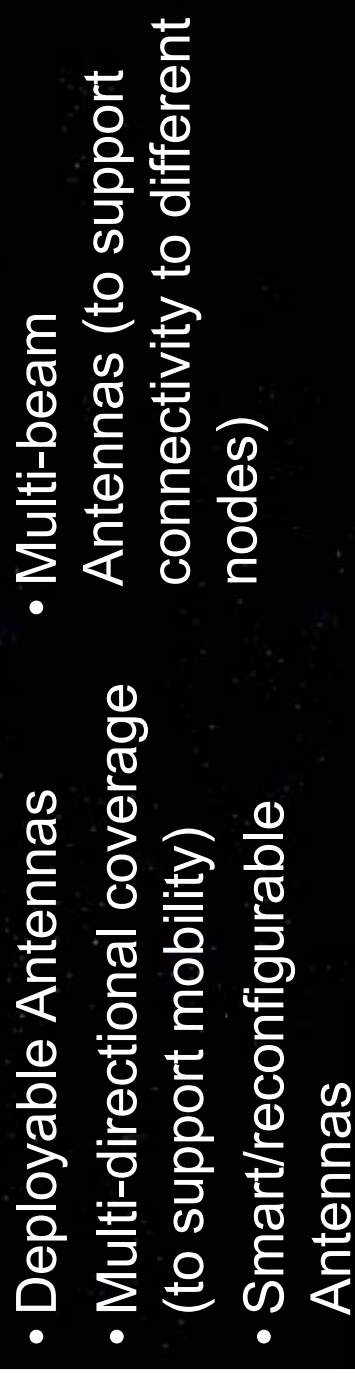 \\
\hline 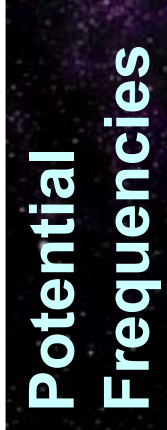 & $\frac{\text { 눈 }}{\frac{1}{5}} \frac{0}{\frac{0}{5}}$ & 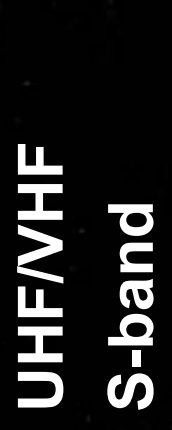 & 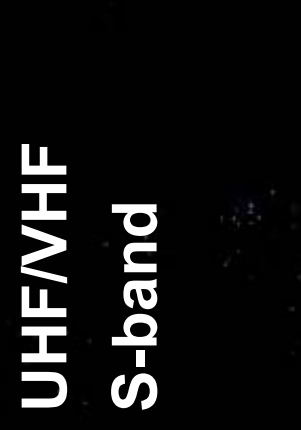 & 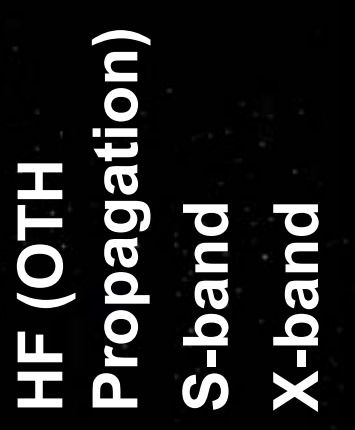 \\
\hline 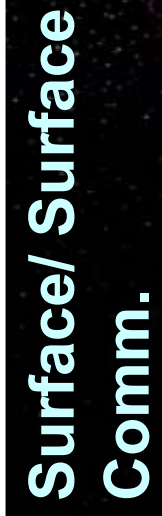 & $\begin{array}{l}\overrightarrow{3} \\
\mathbb{S} \\
\mathbb{4}\end{array}$ & $\frac{5}{0}$ & $\begin{array}{l}\frac{1}{0} \\
\frac{0}{2} \\
\frac{2}{2}\end{array}$ & 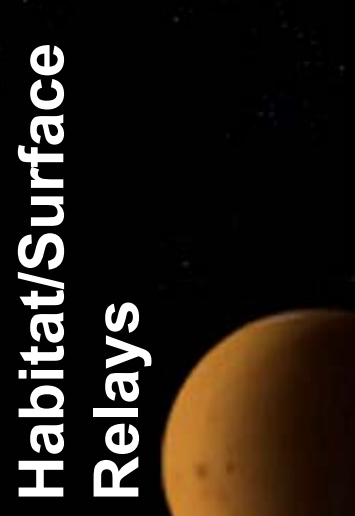 \\
\hline
\end{tabular}




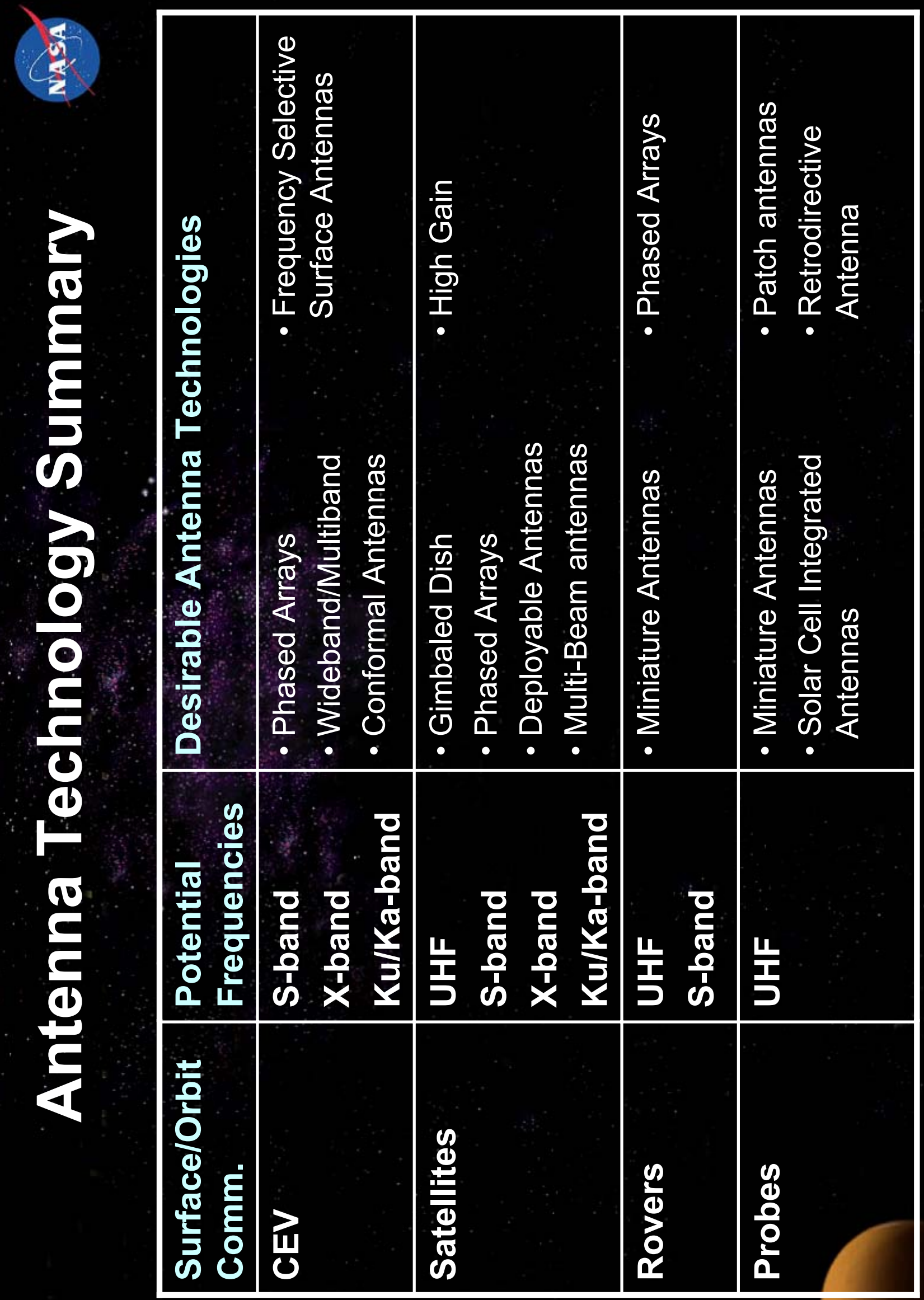




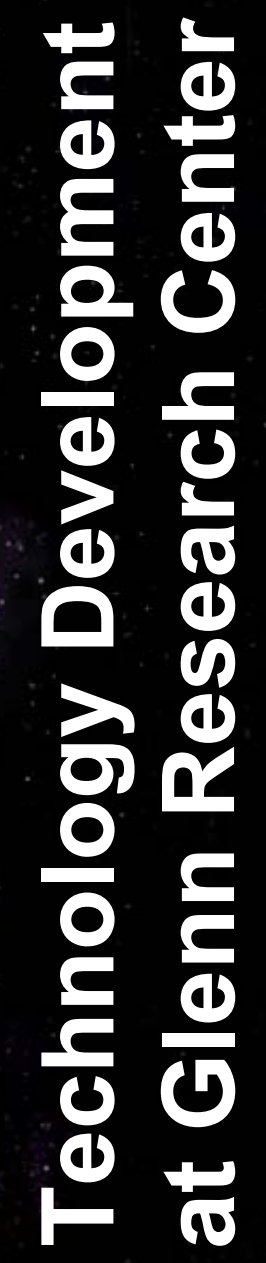




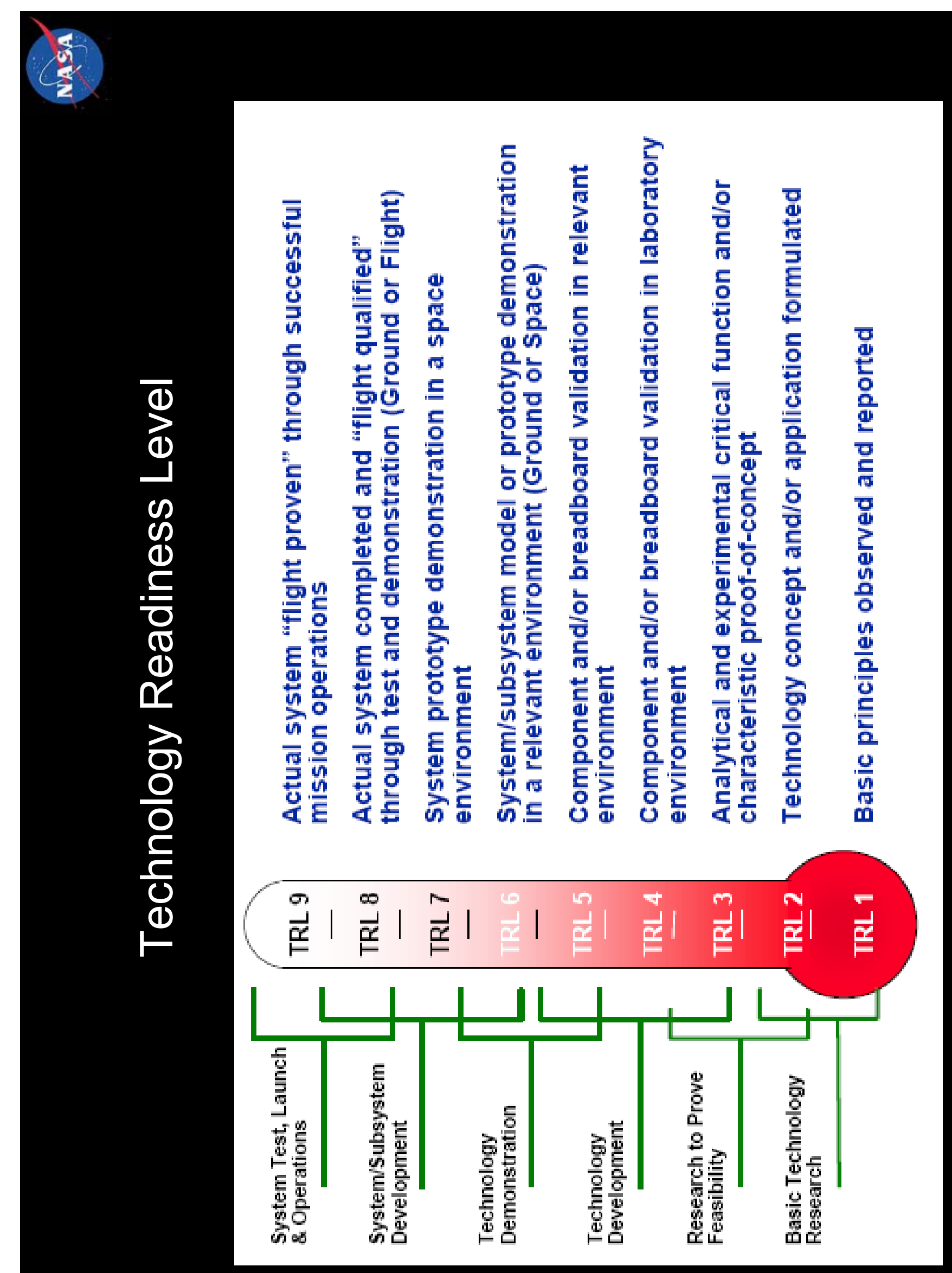




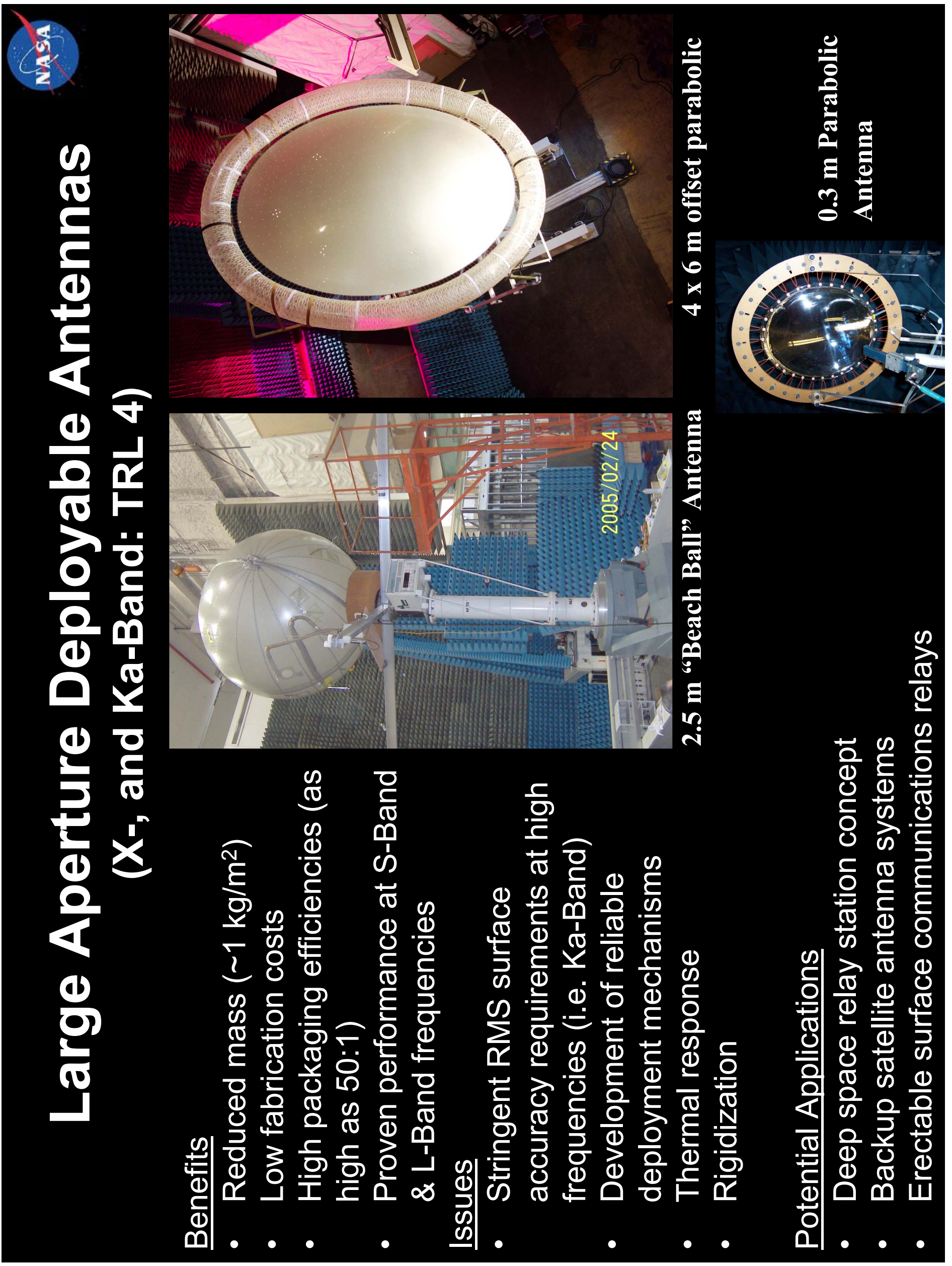




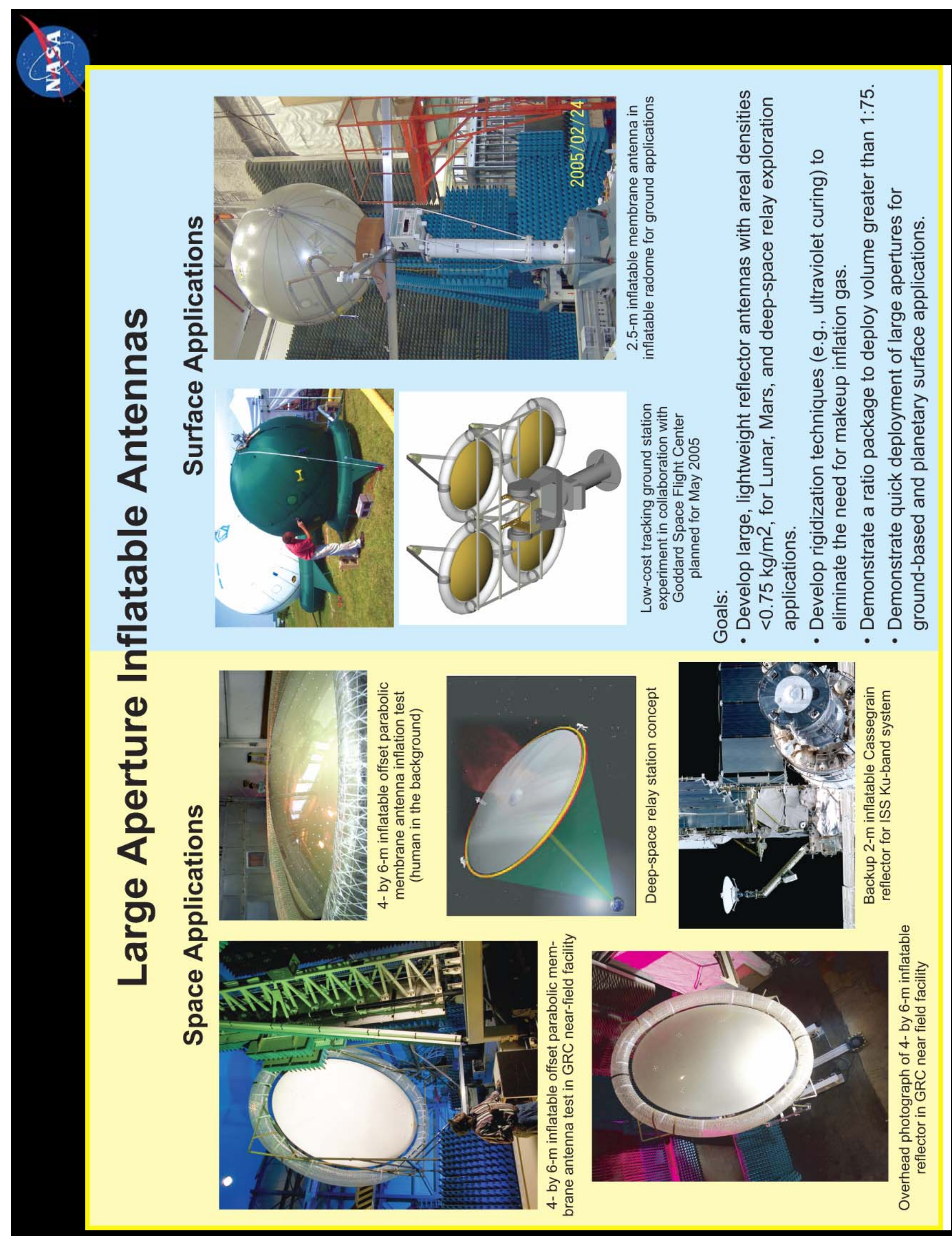



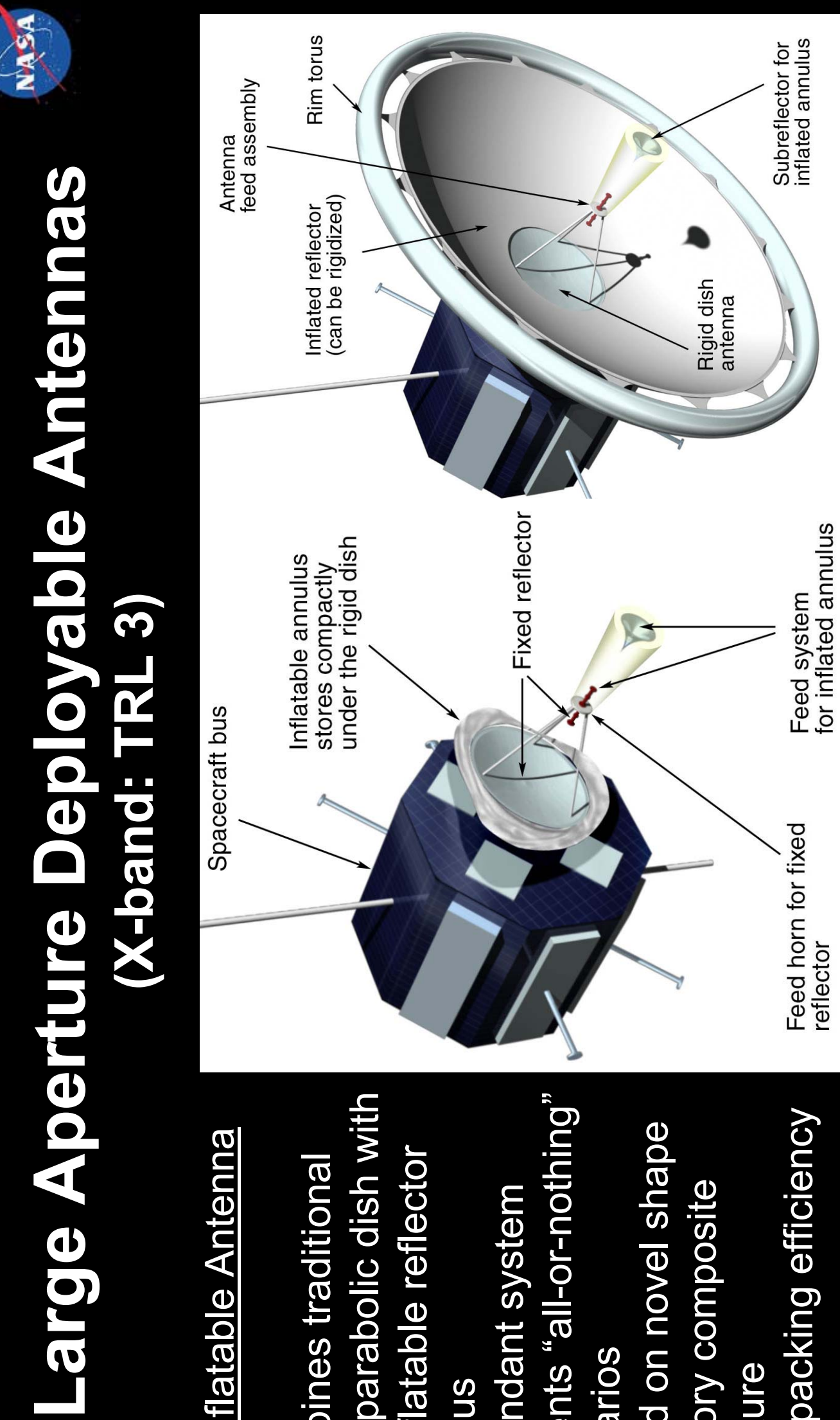

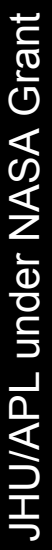
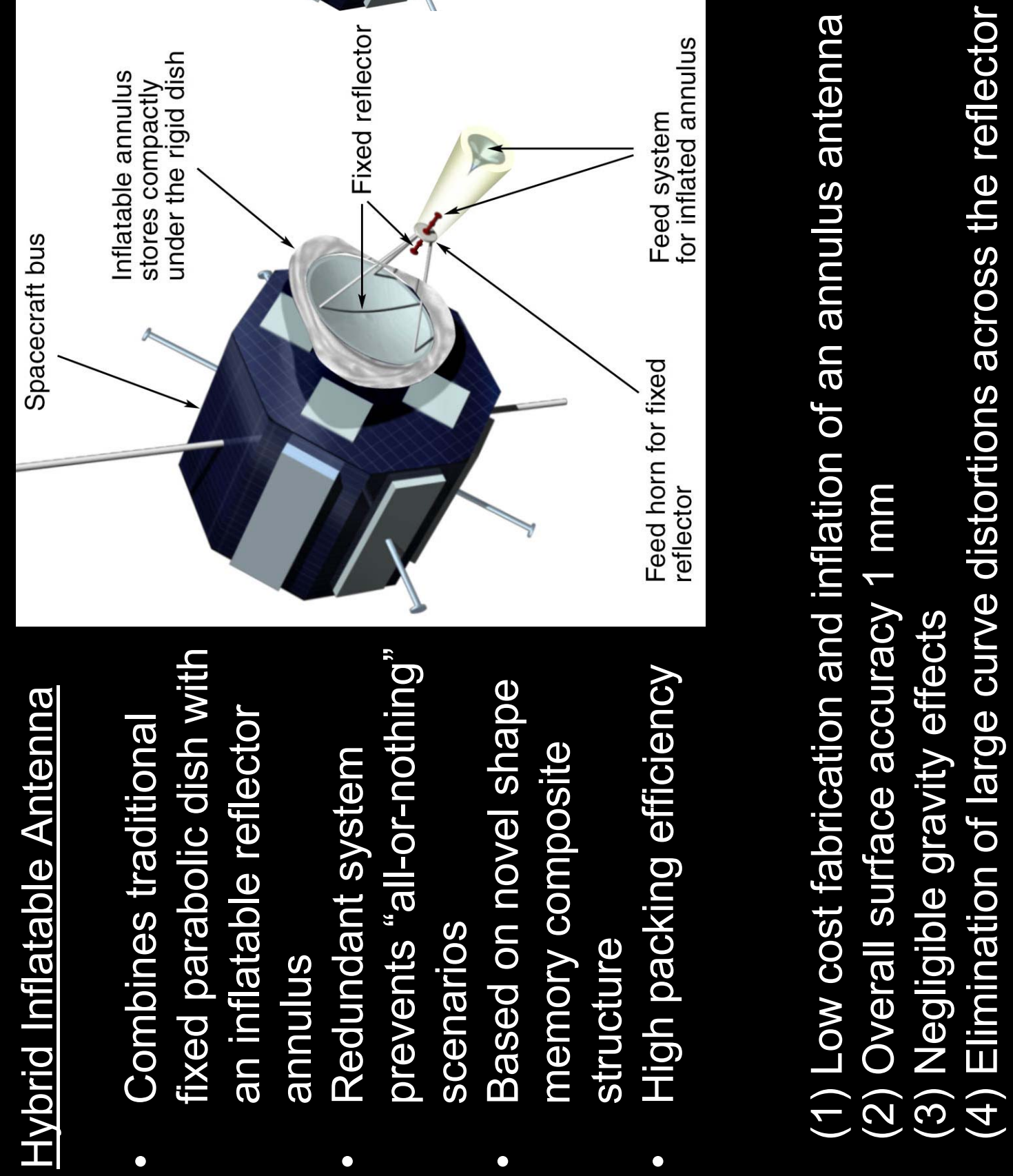


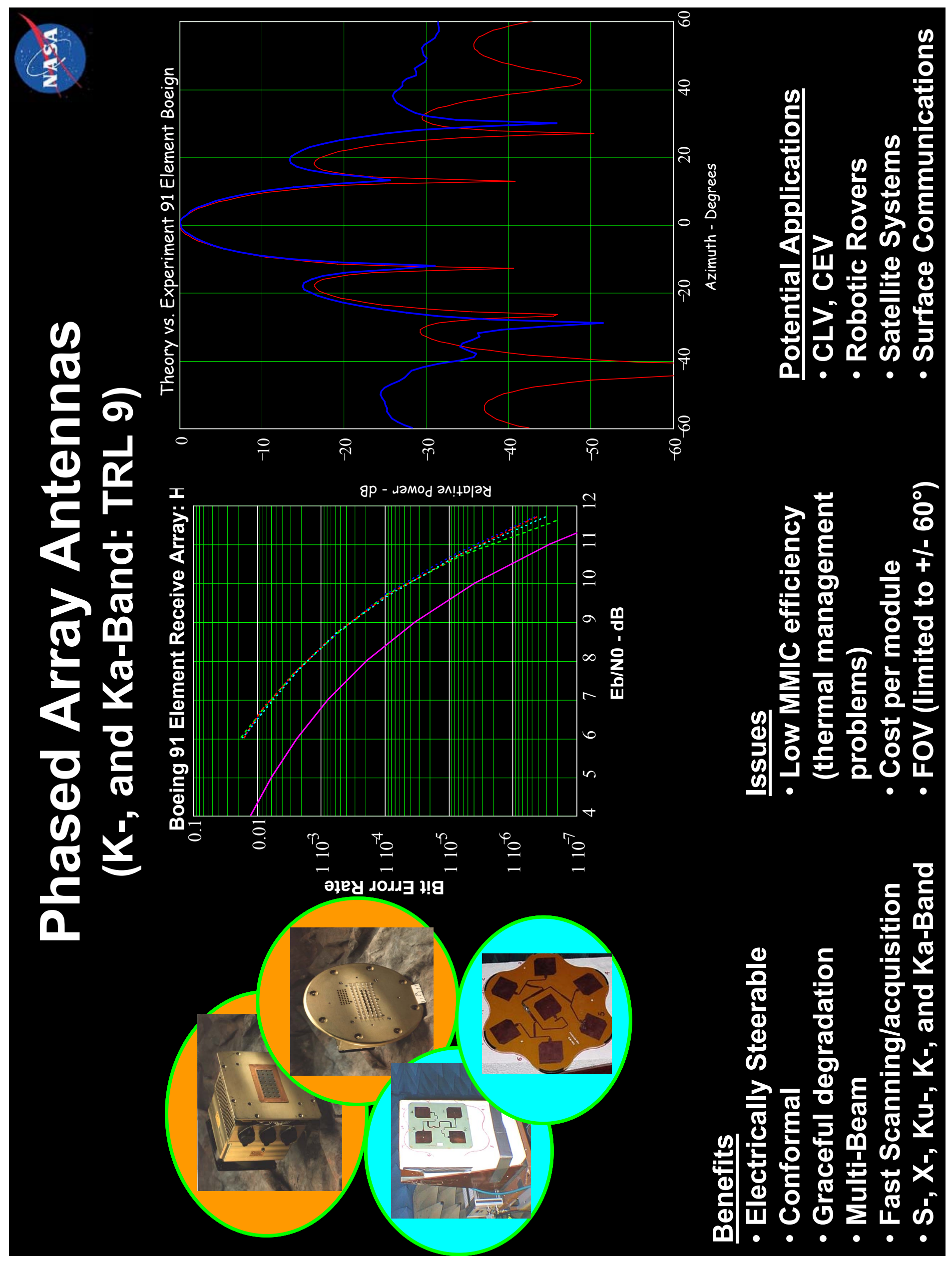




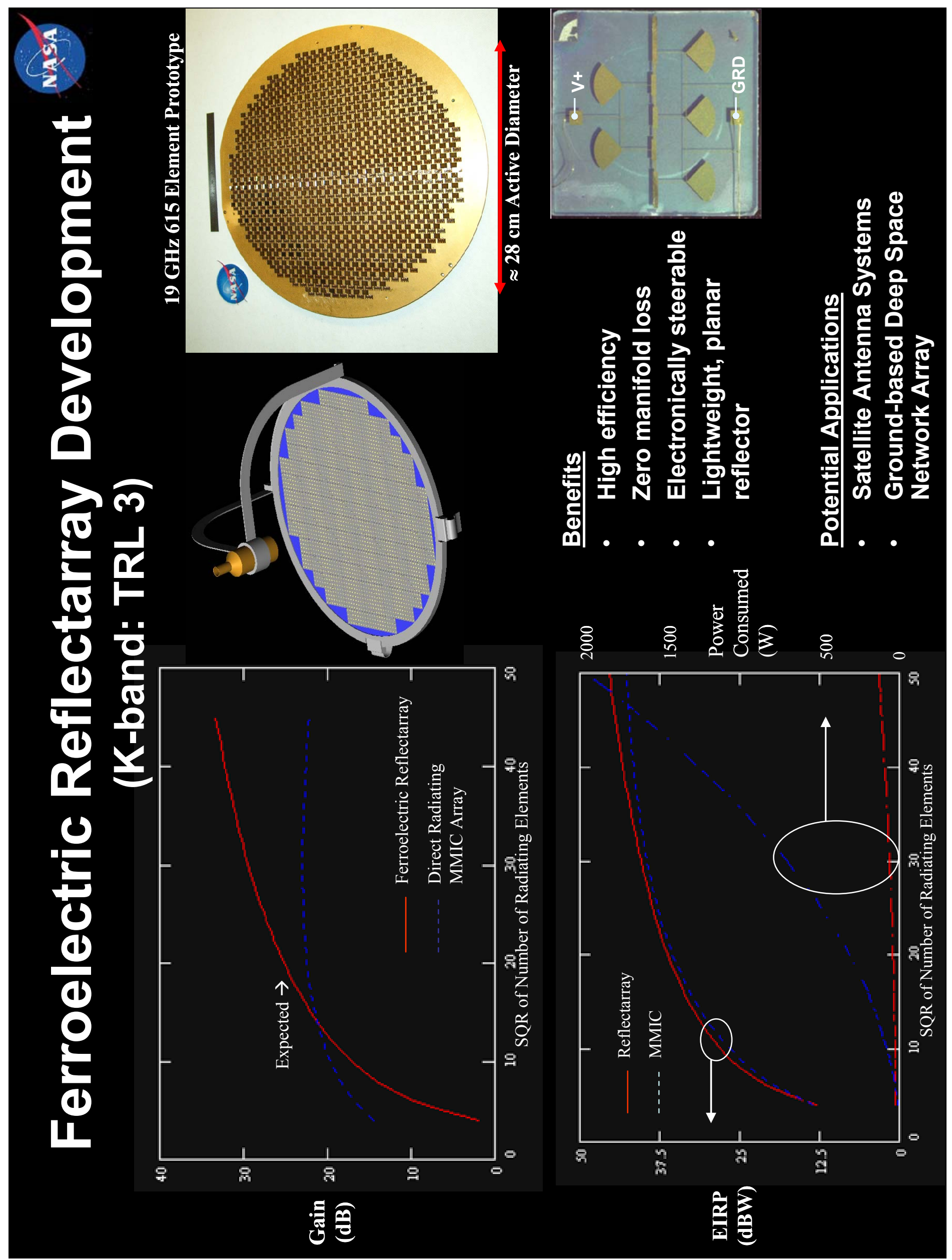



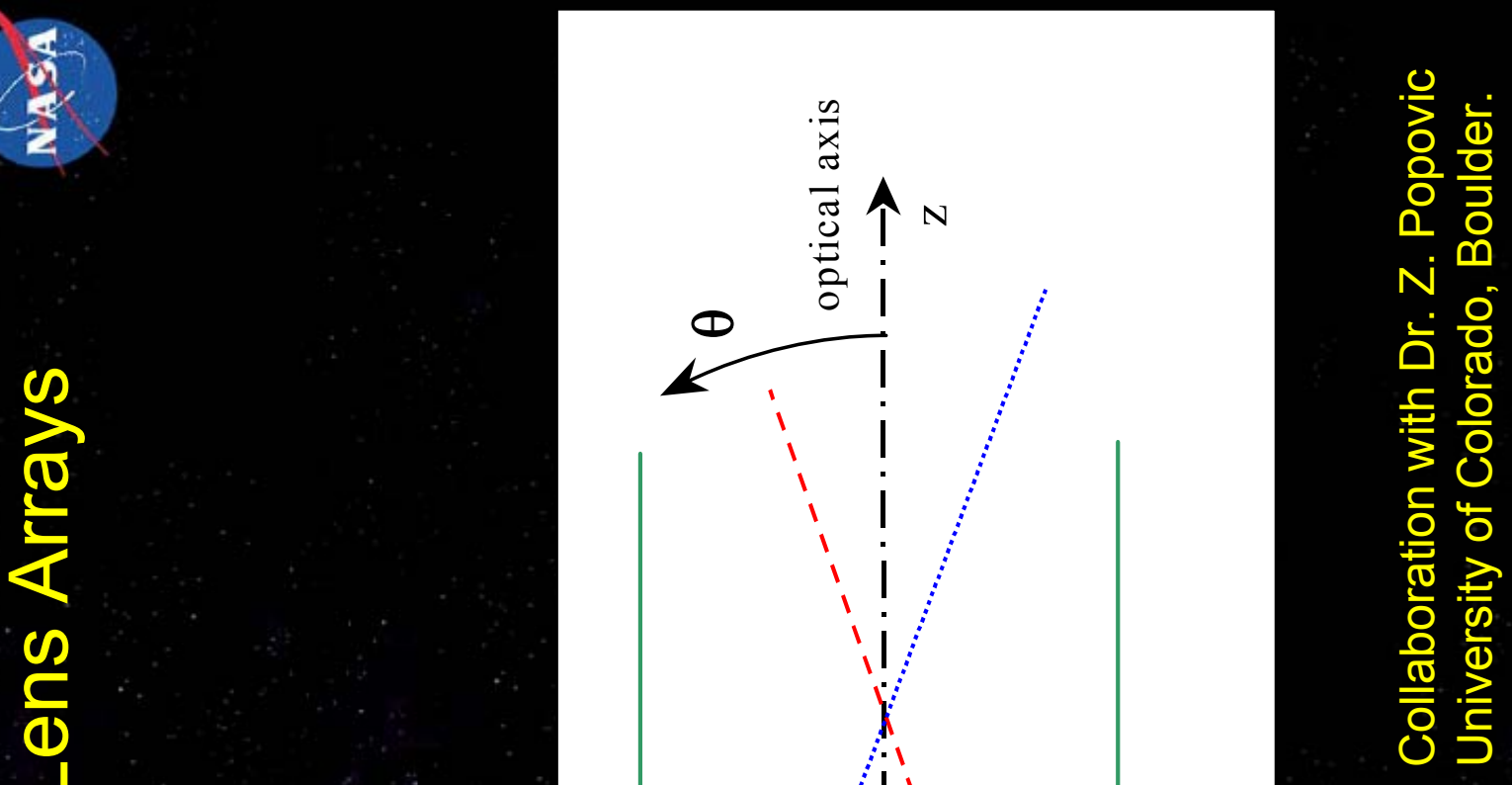

$\frac{1}{10}$

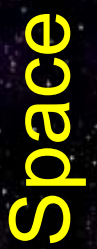

$\frac{1}{\frac{1}{0}}$
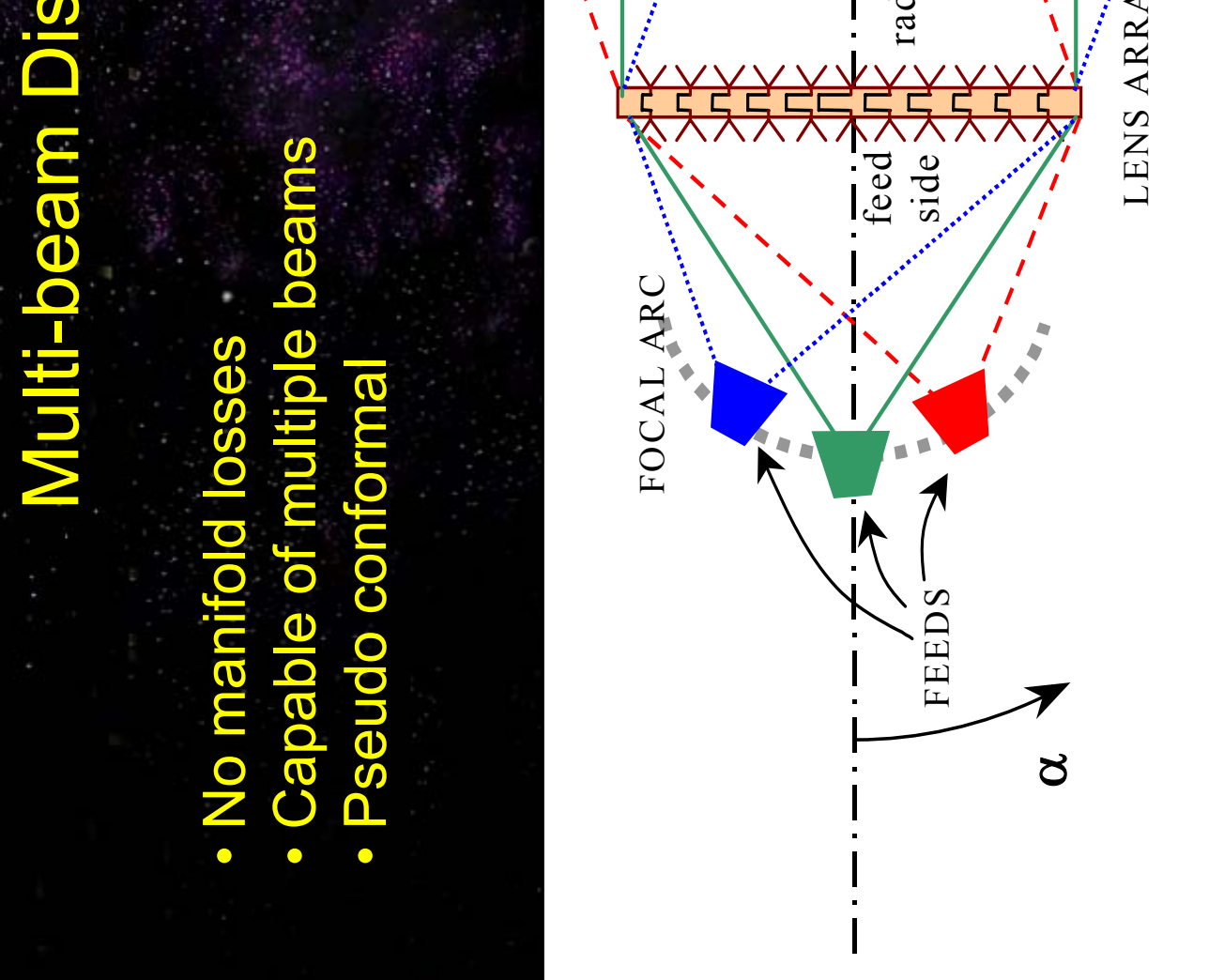


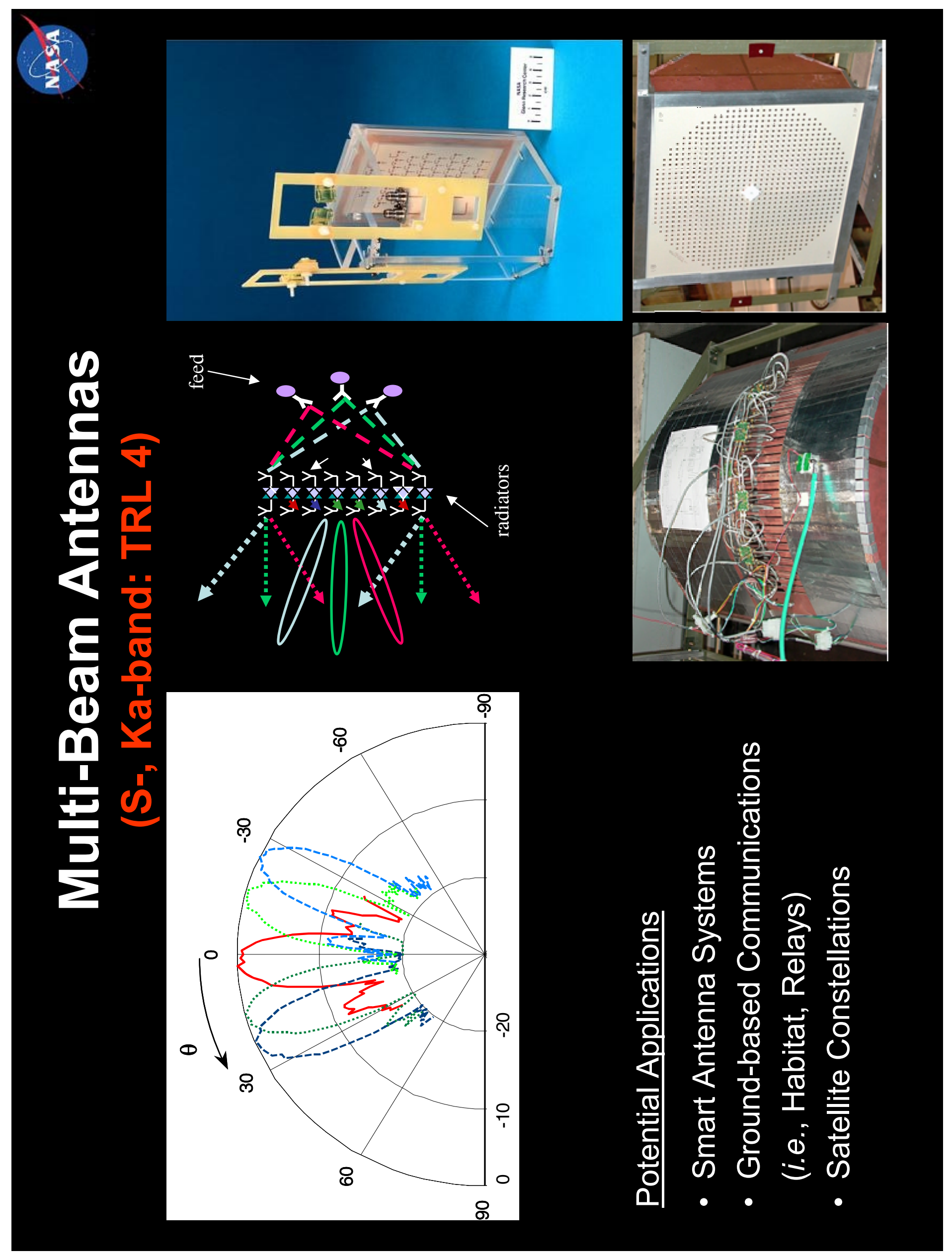




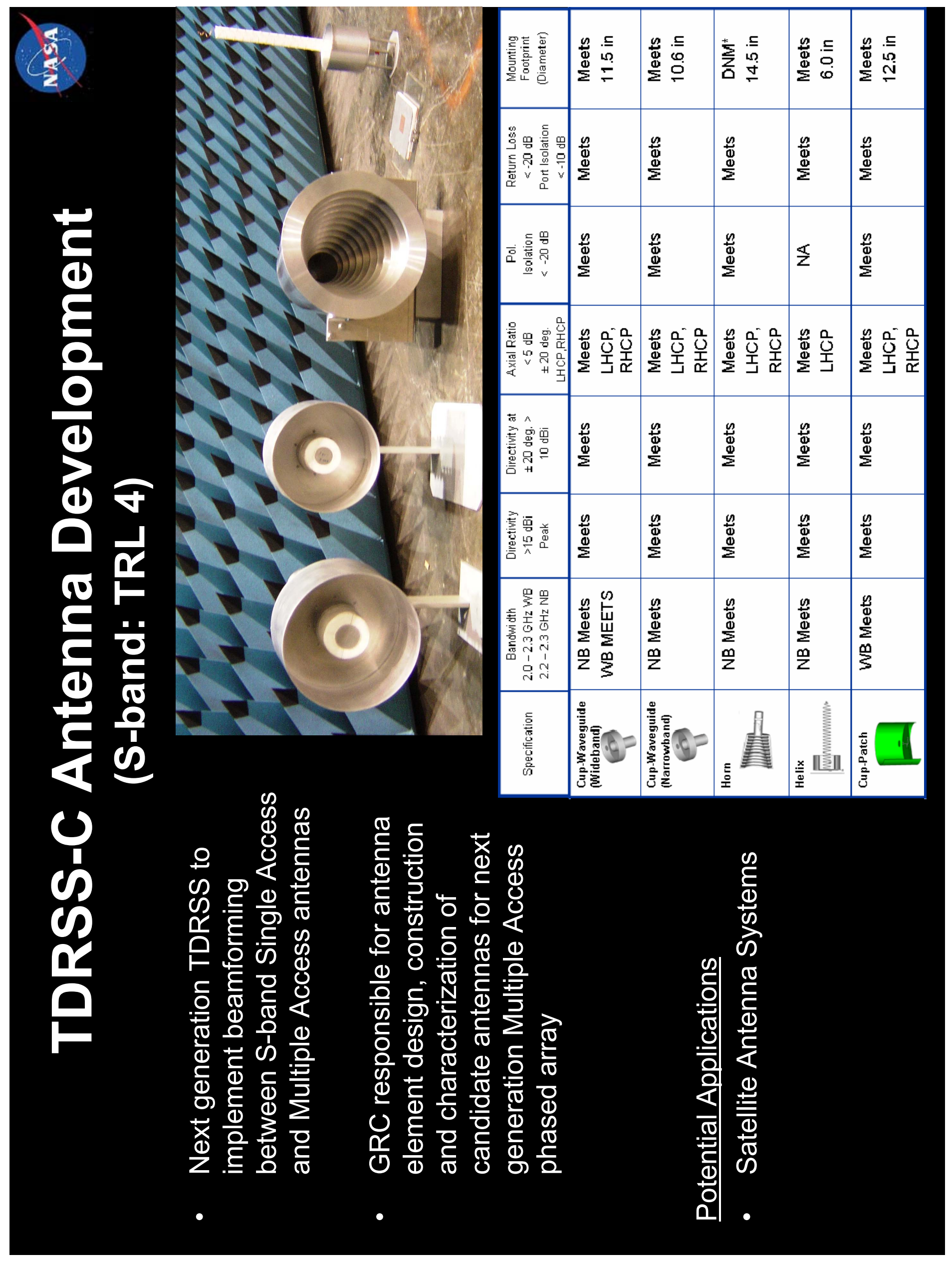




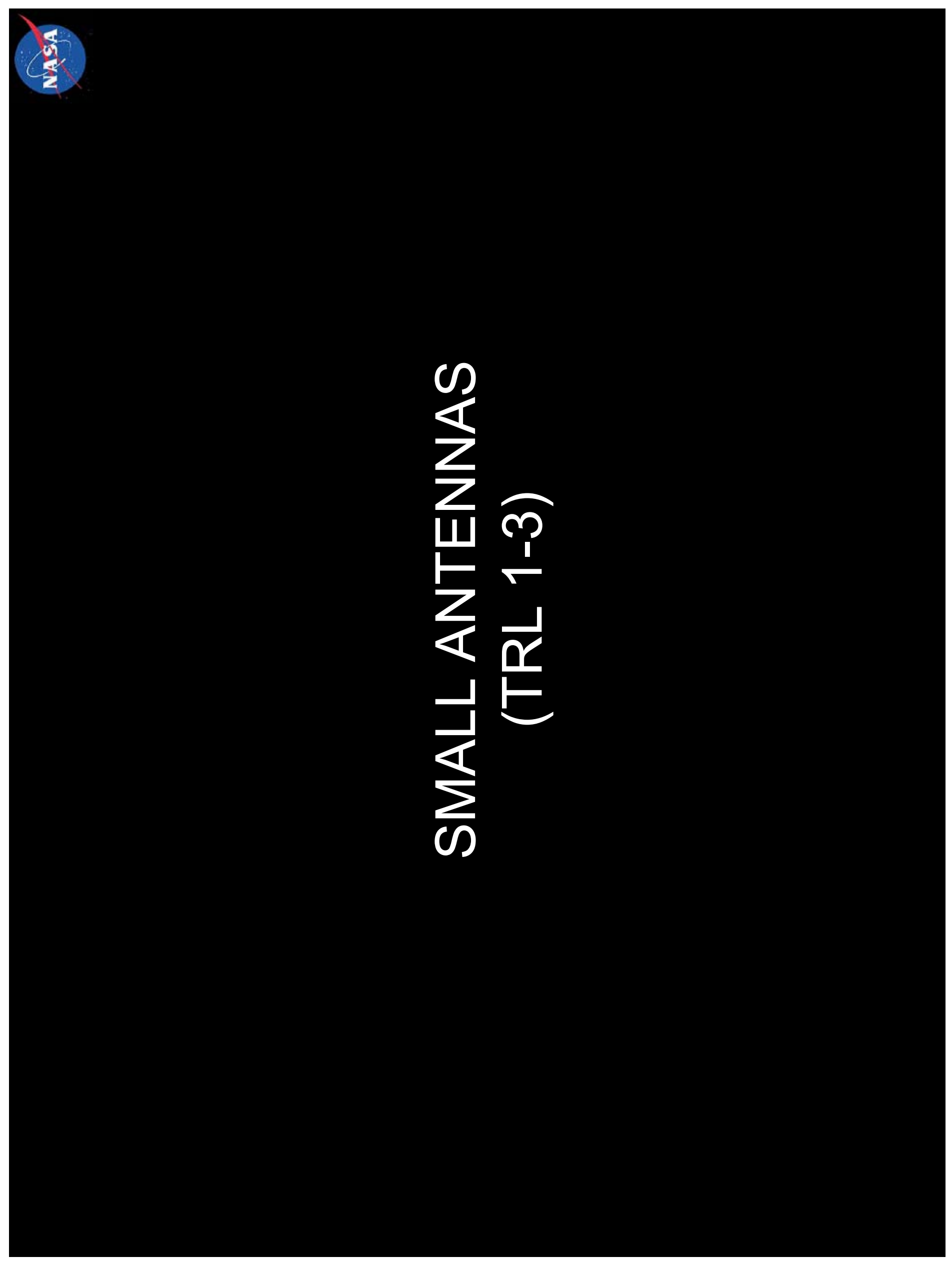




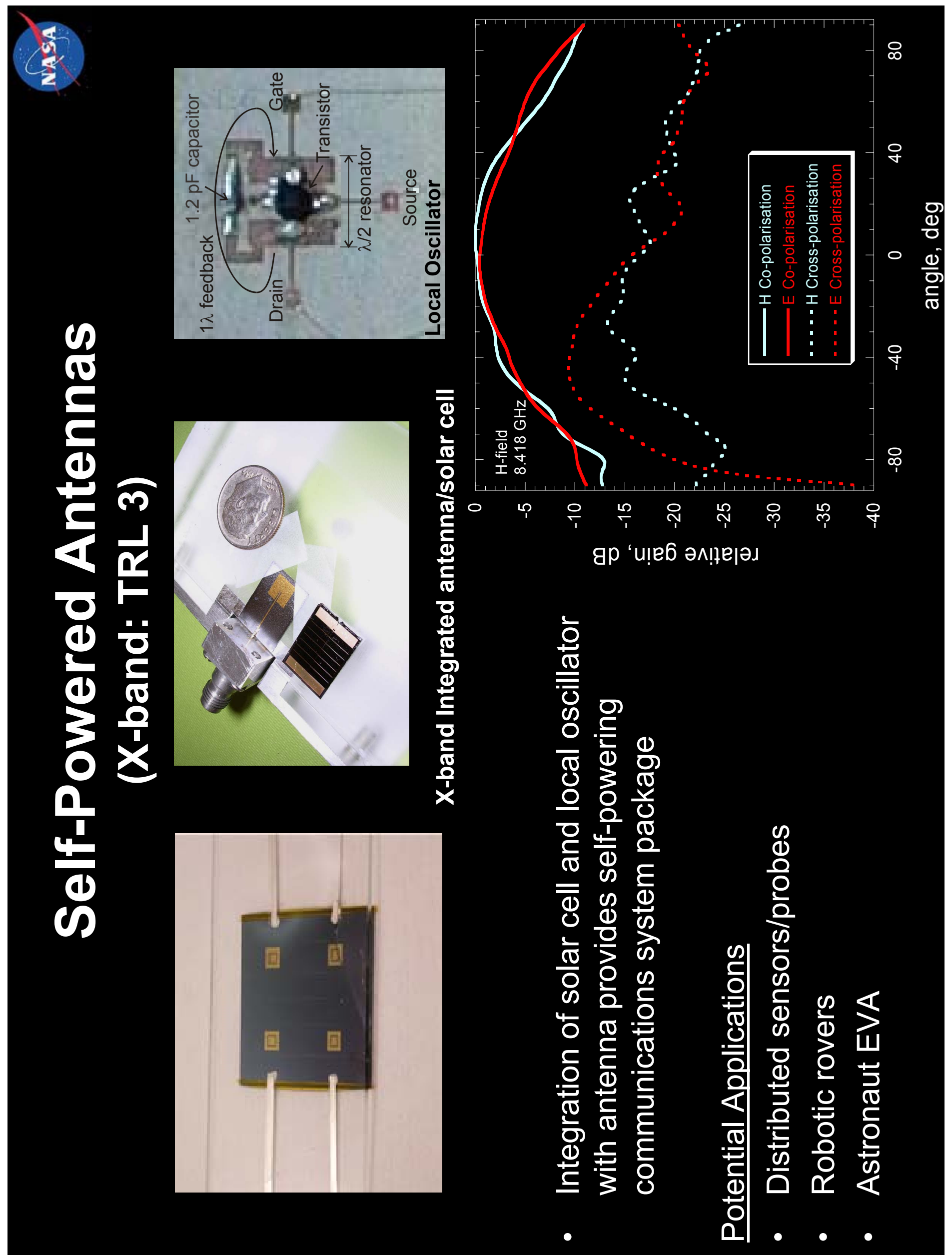




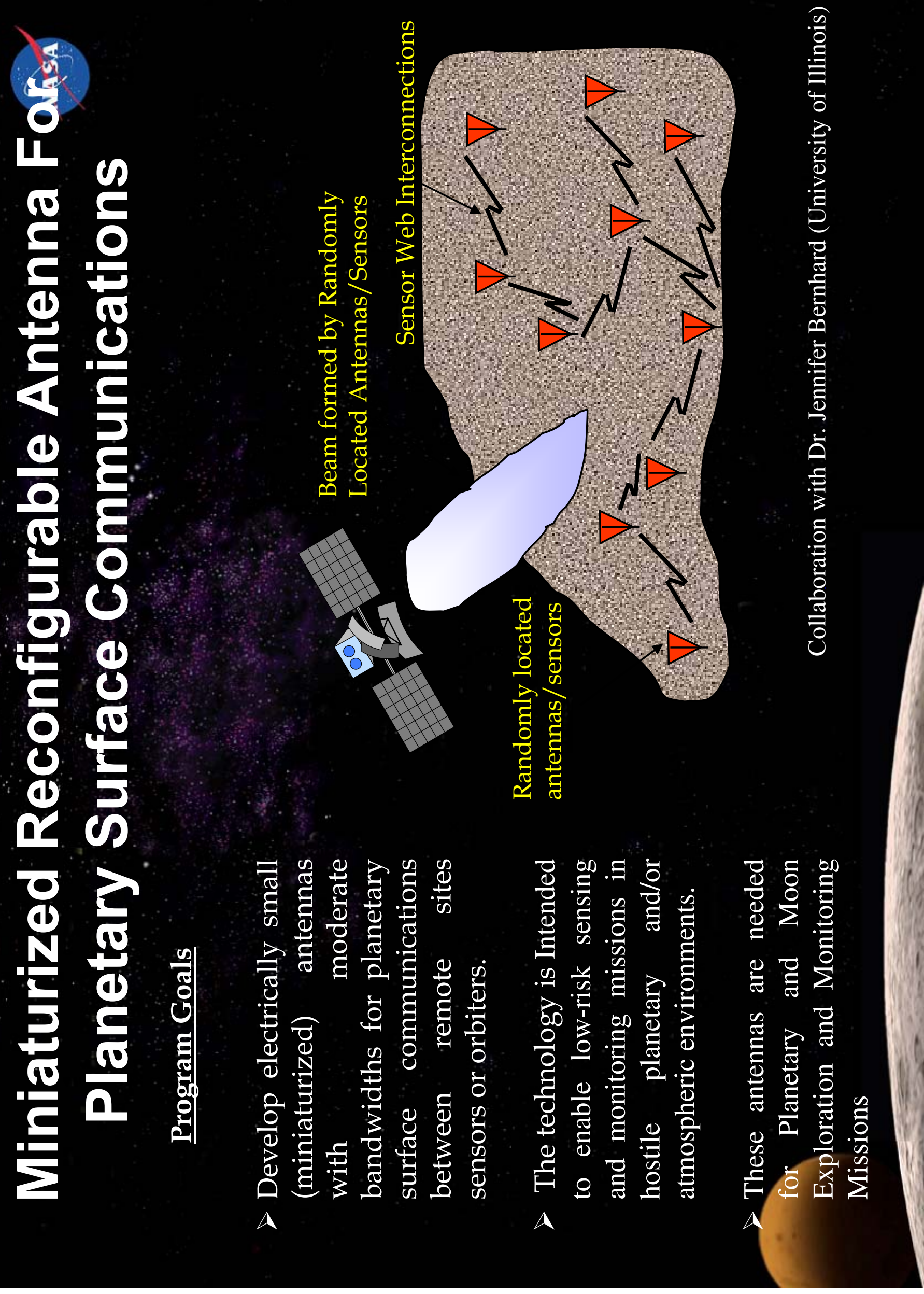




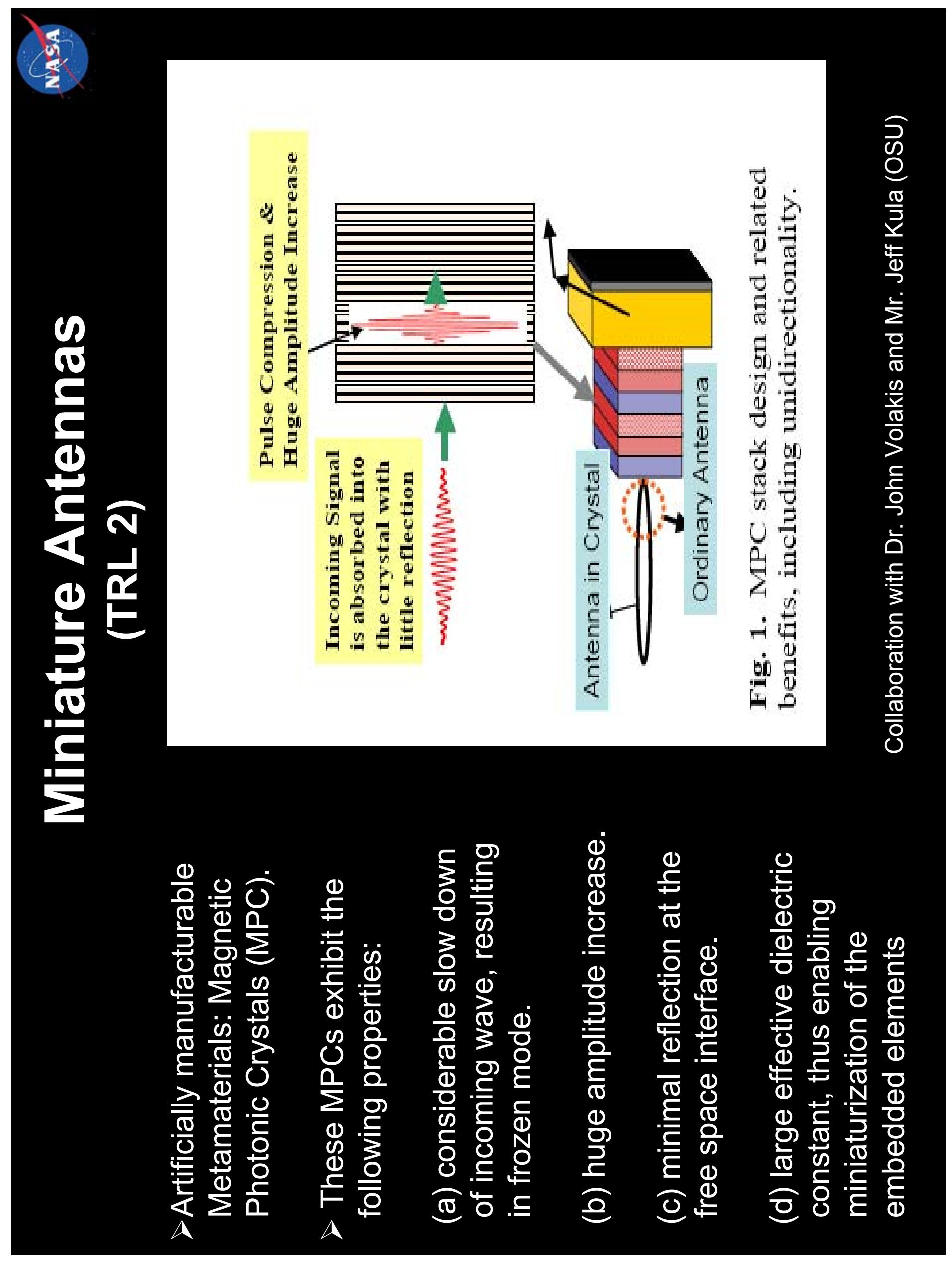




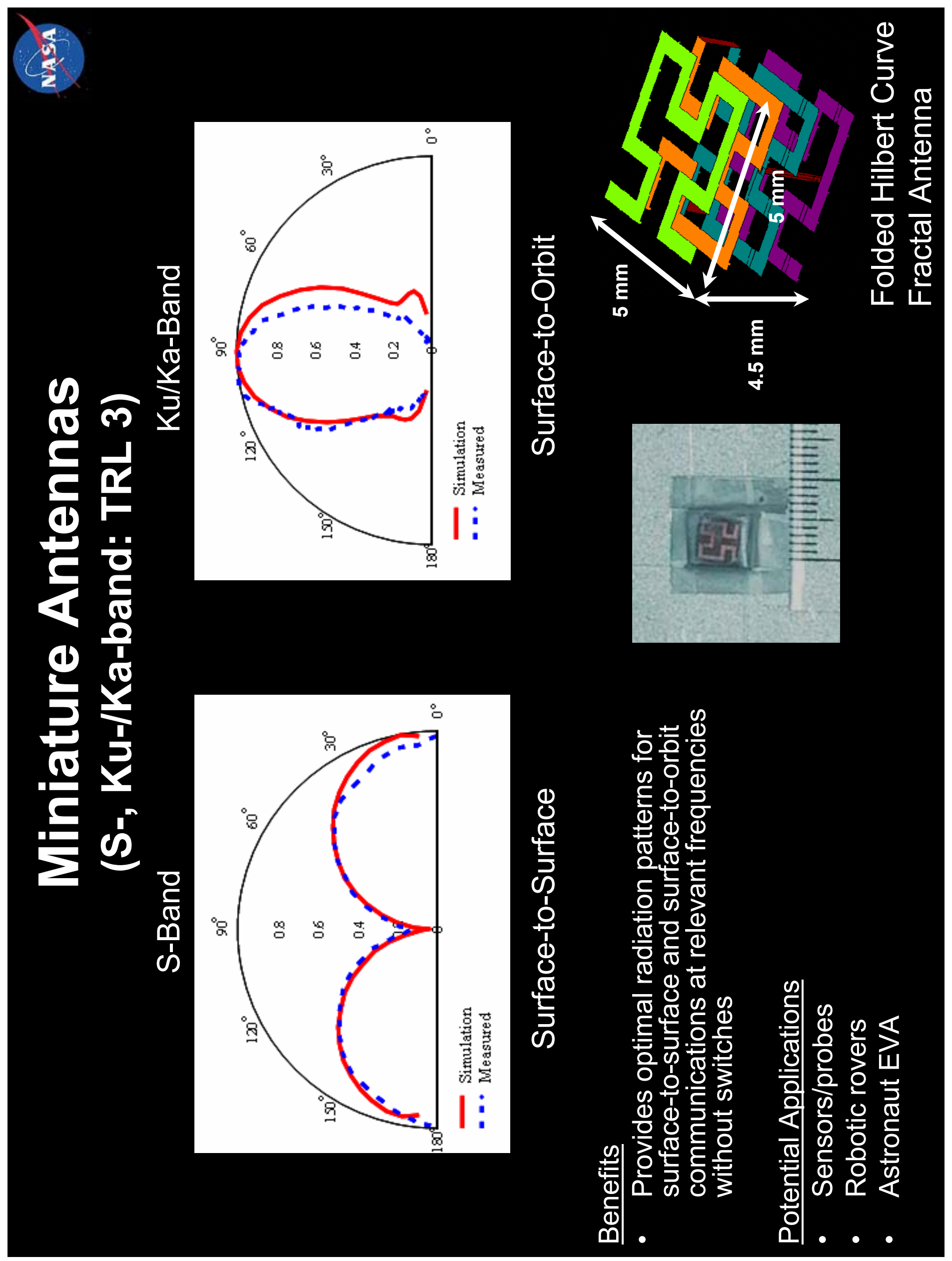




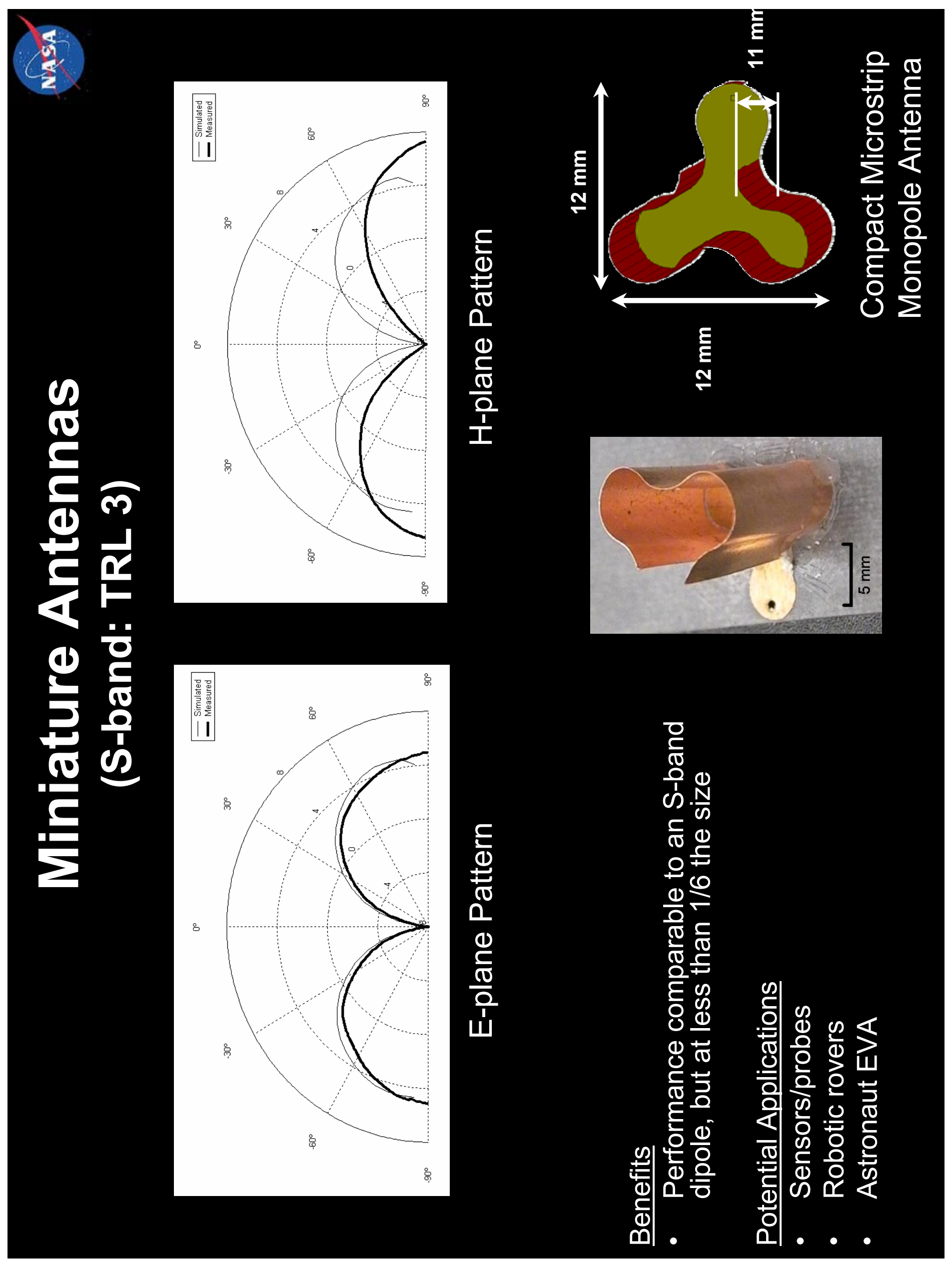




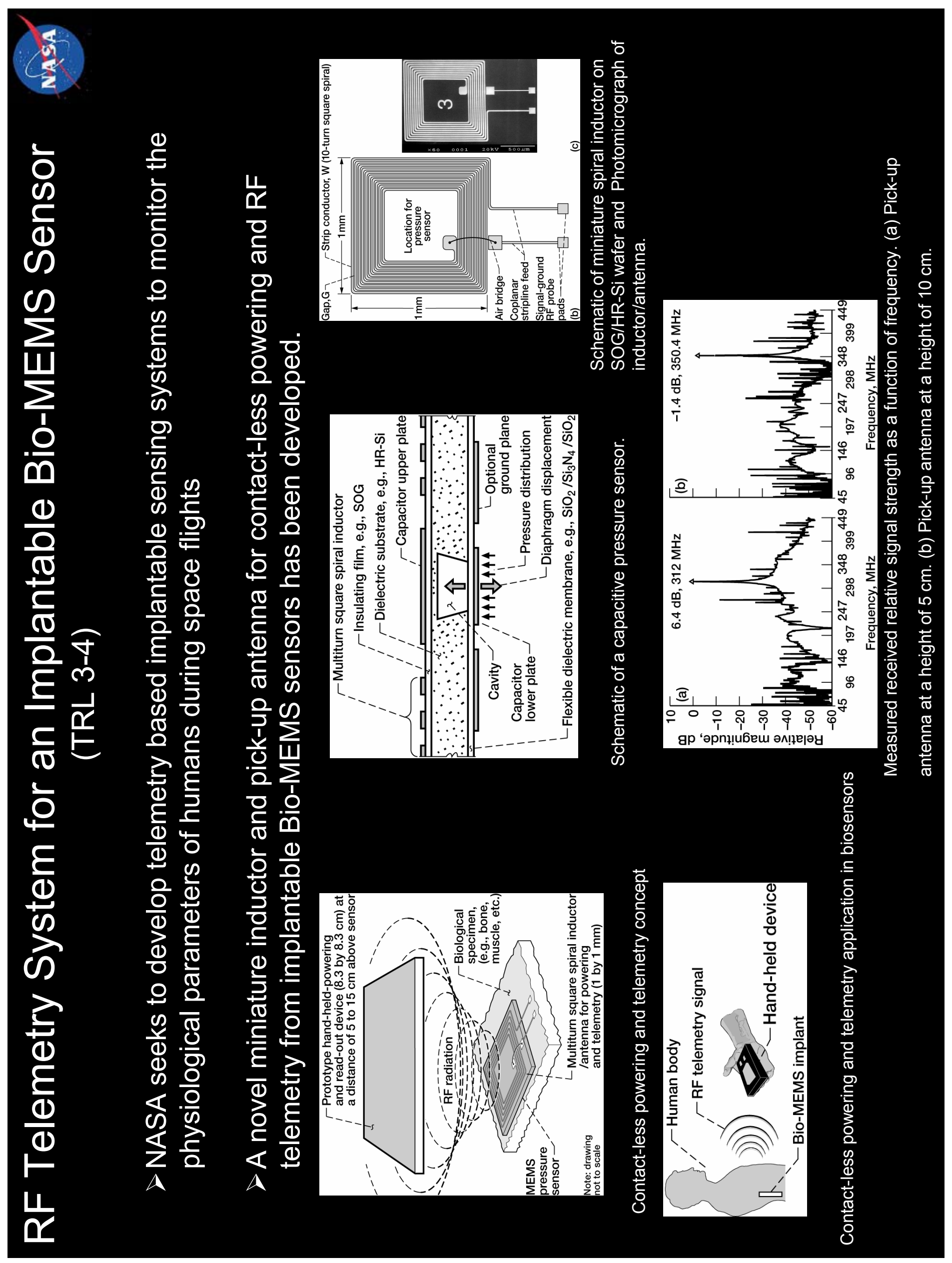




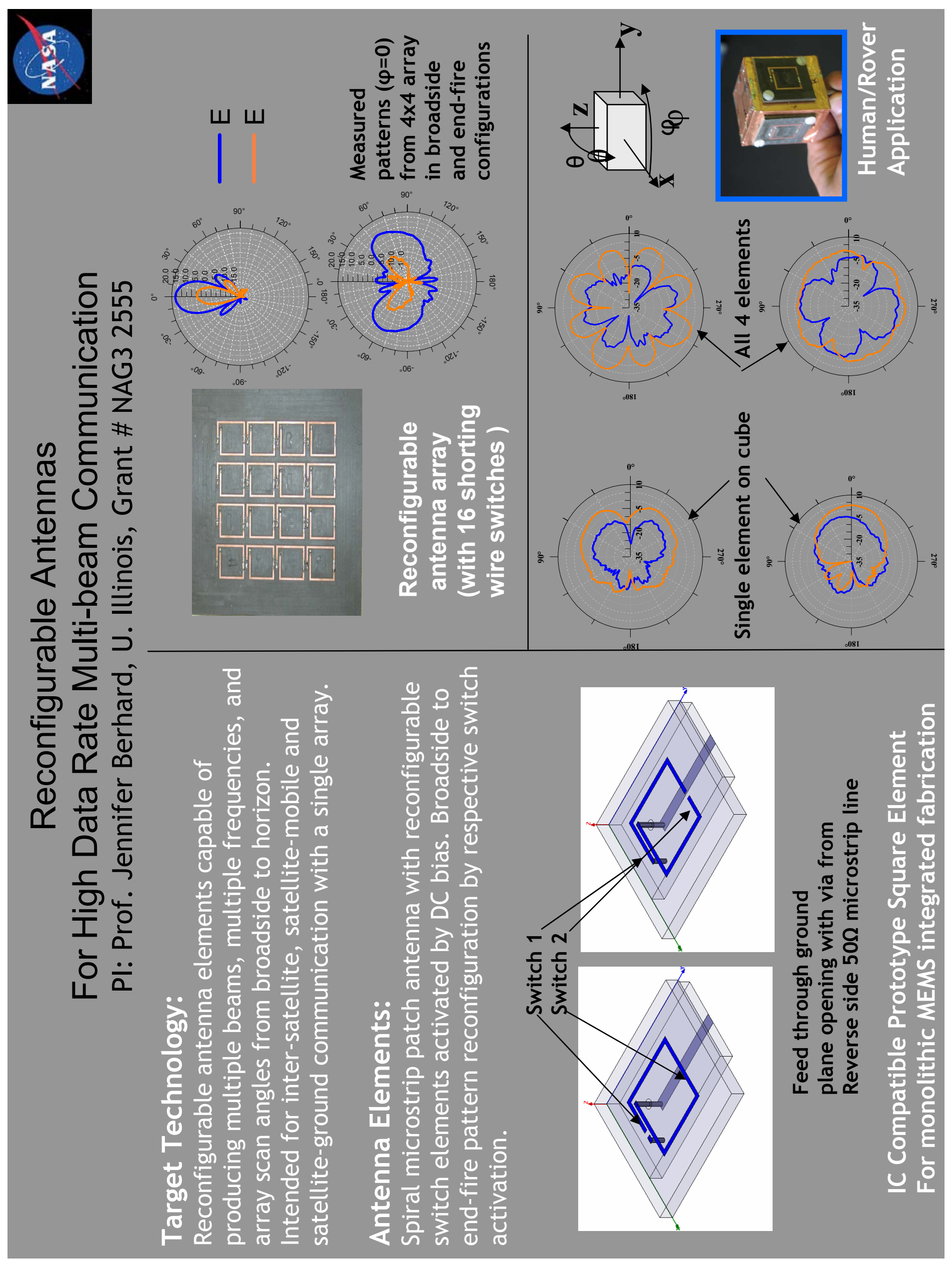




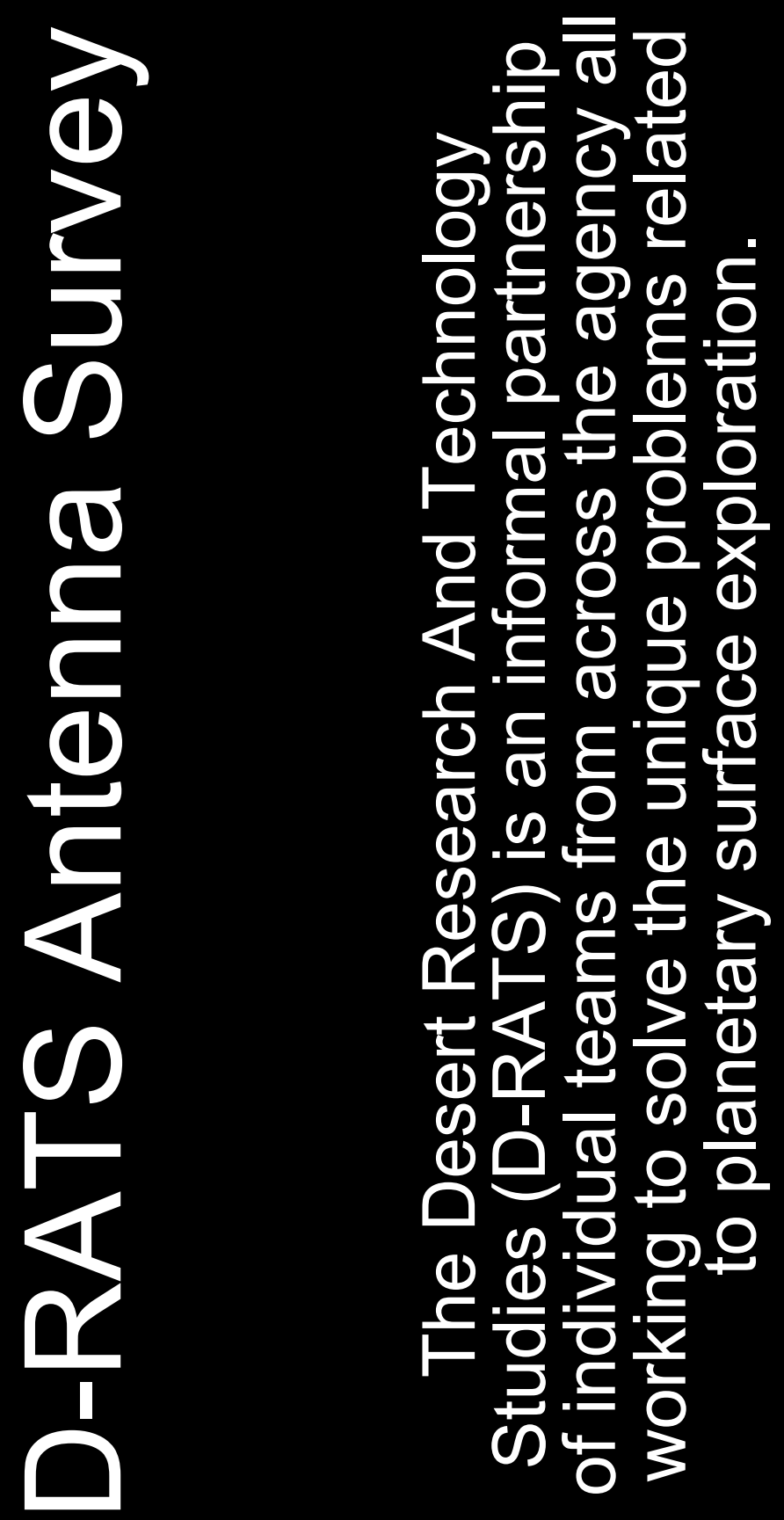




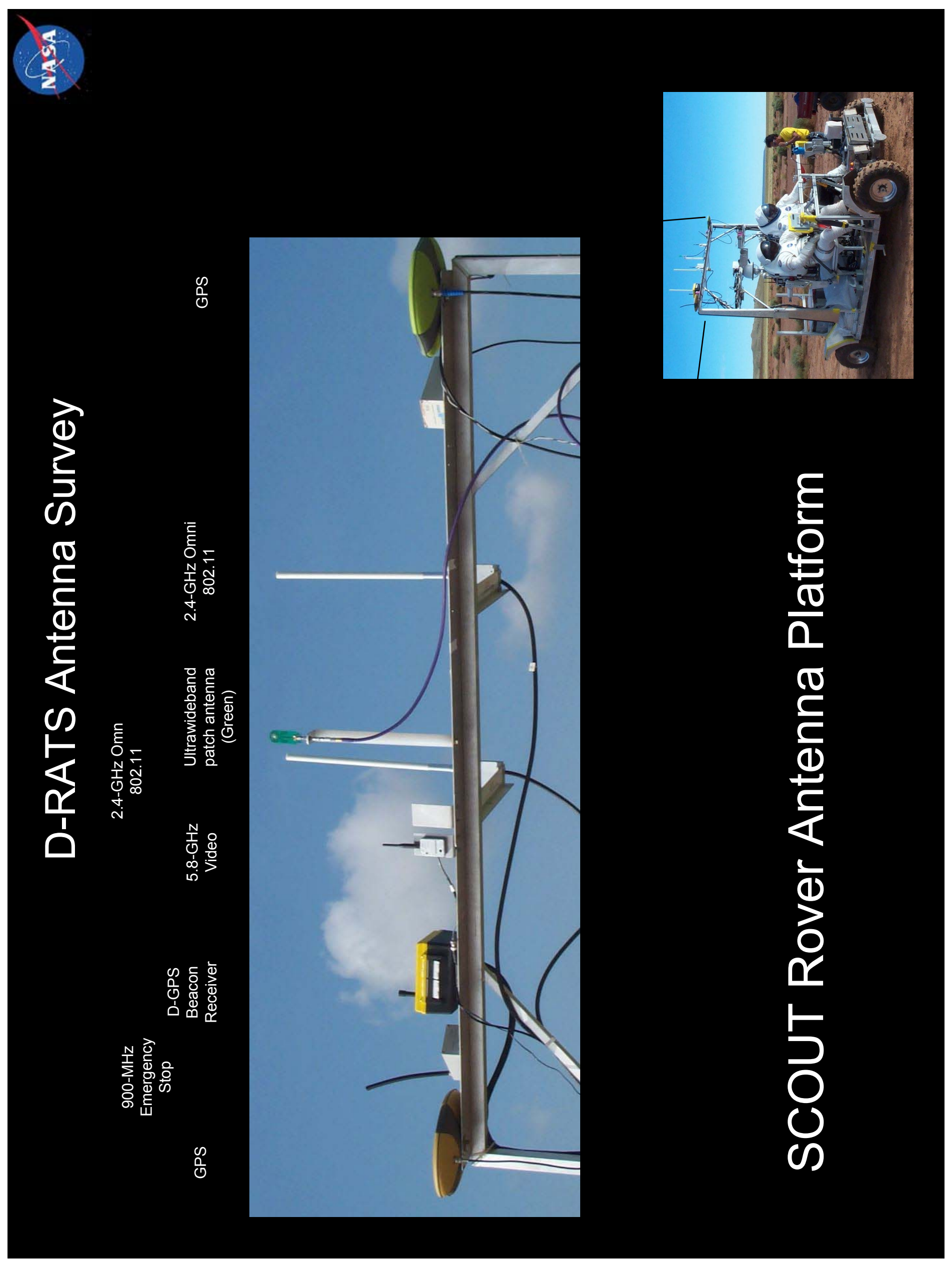




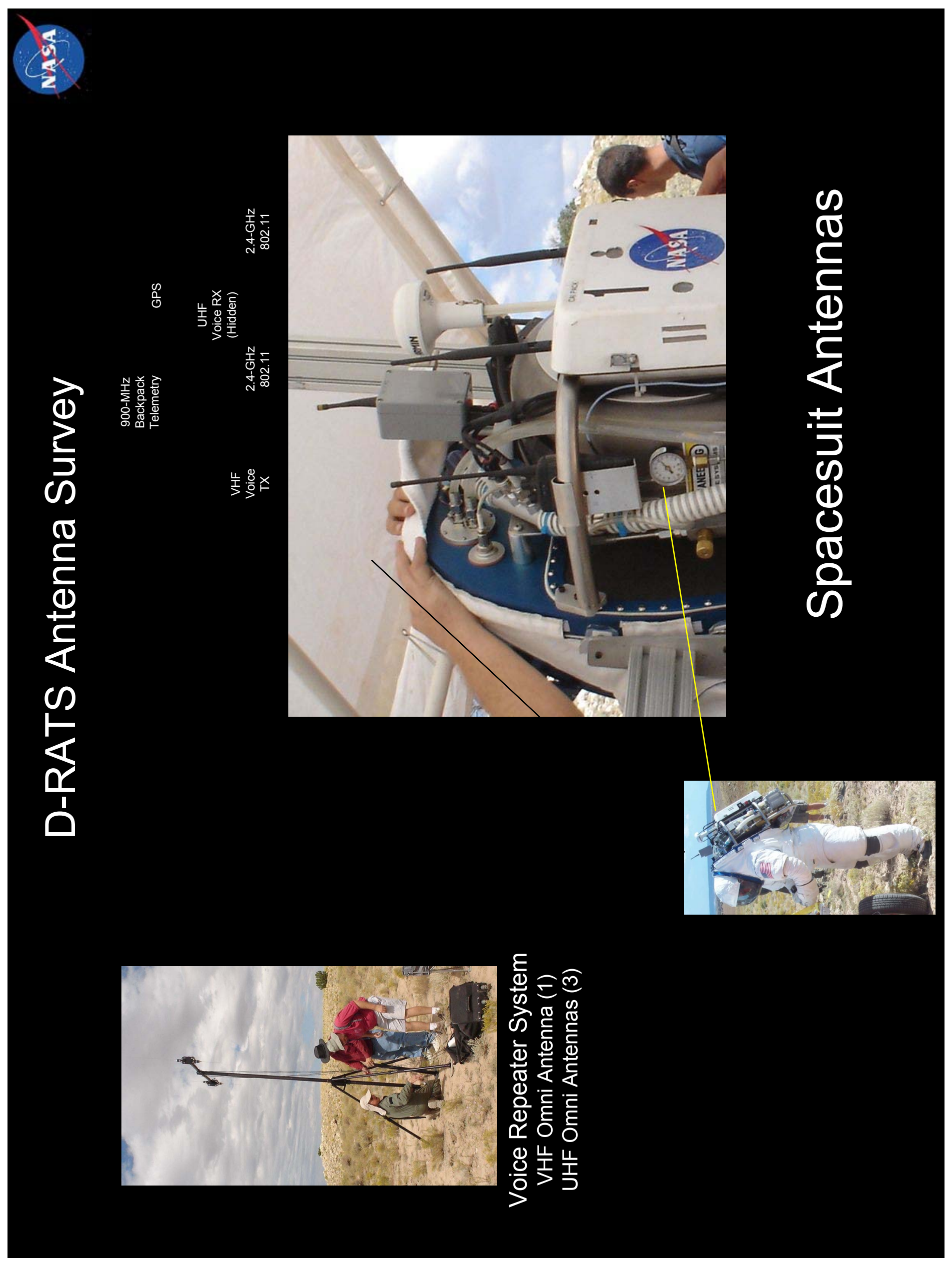




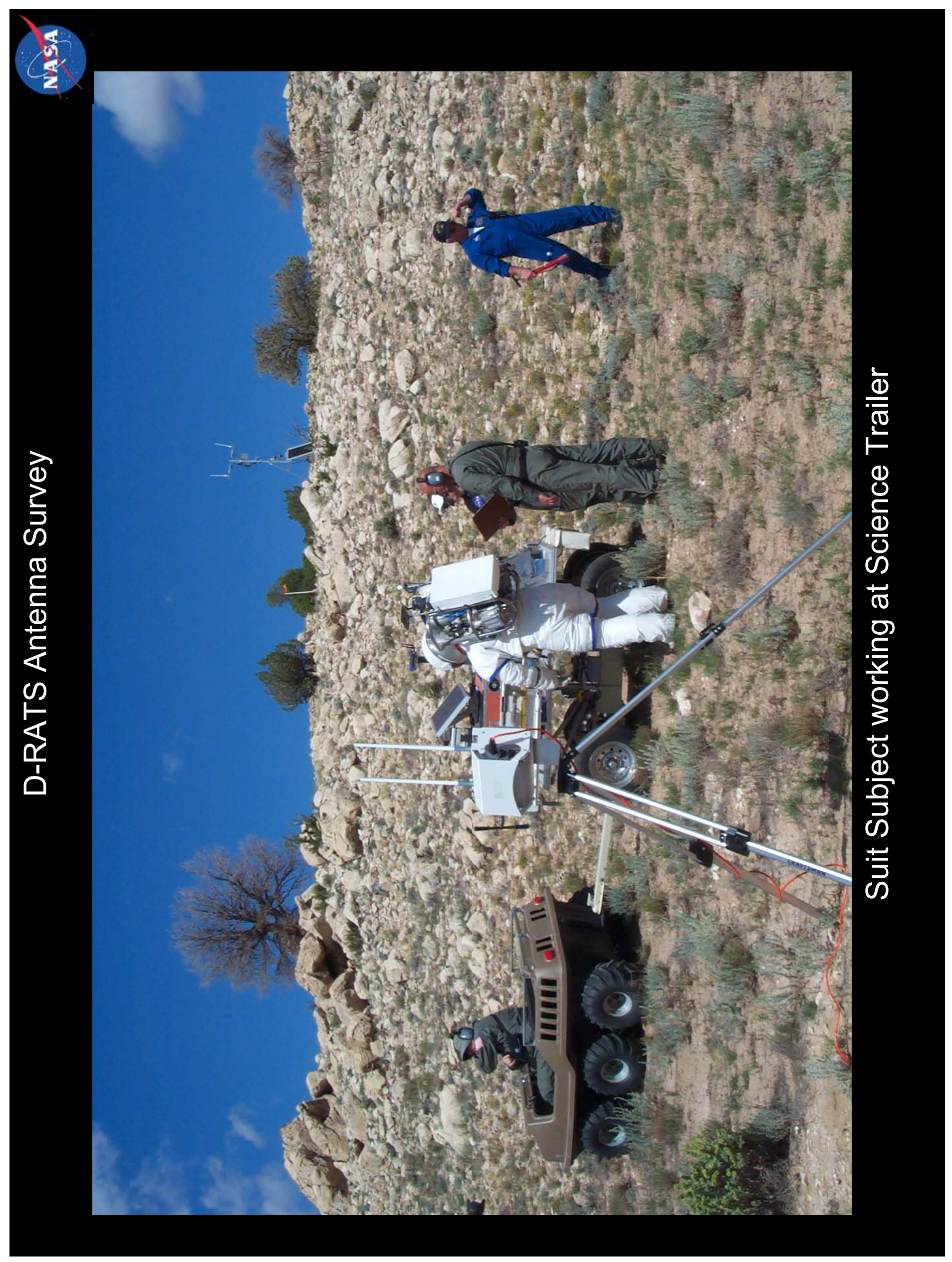




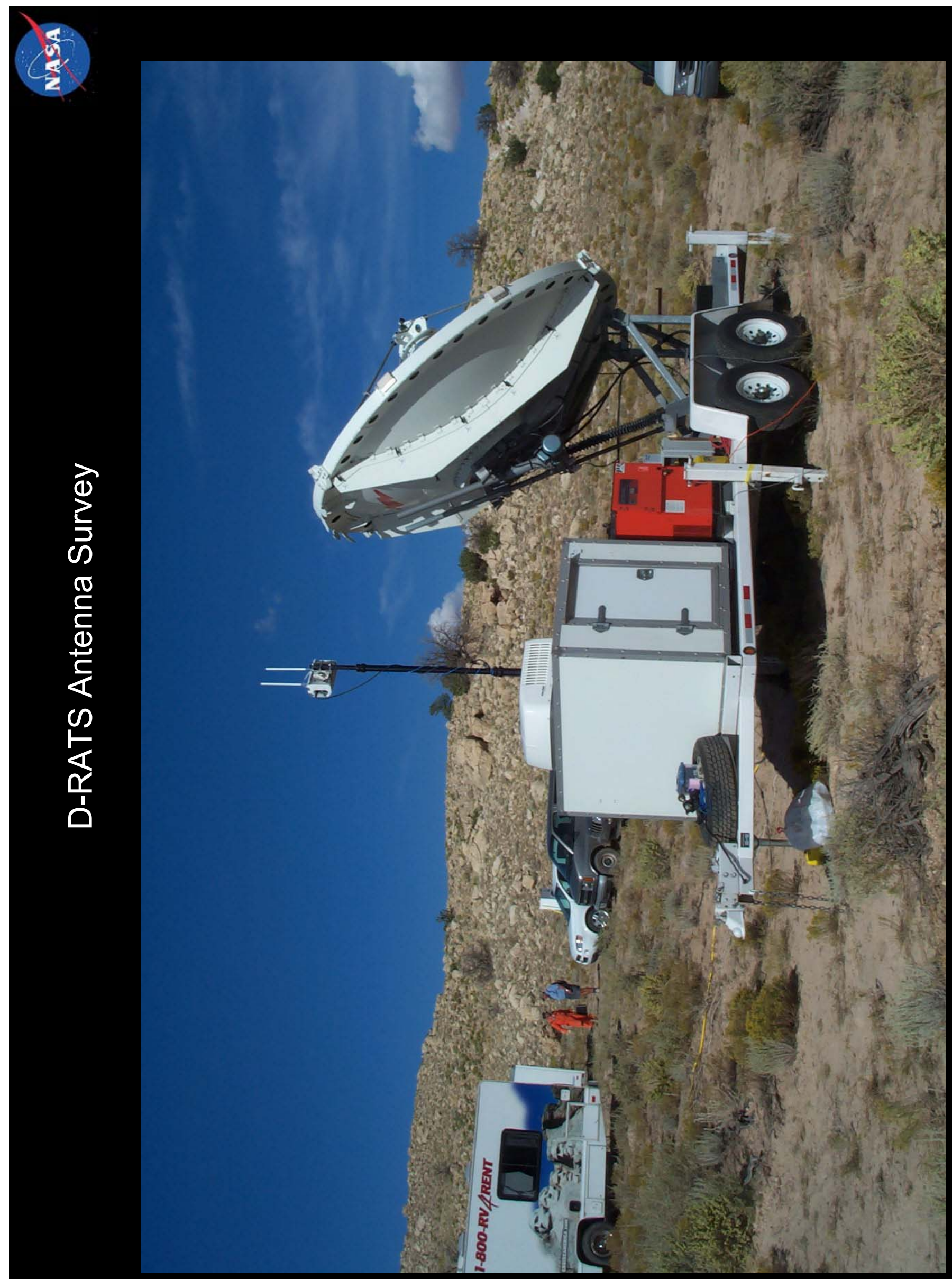




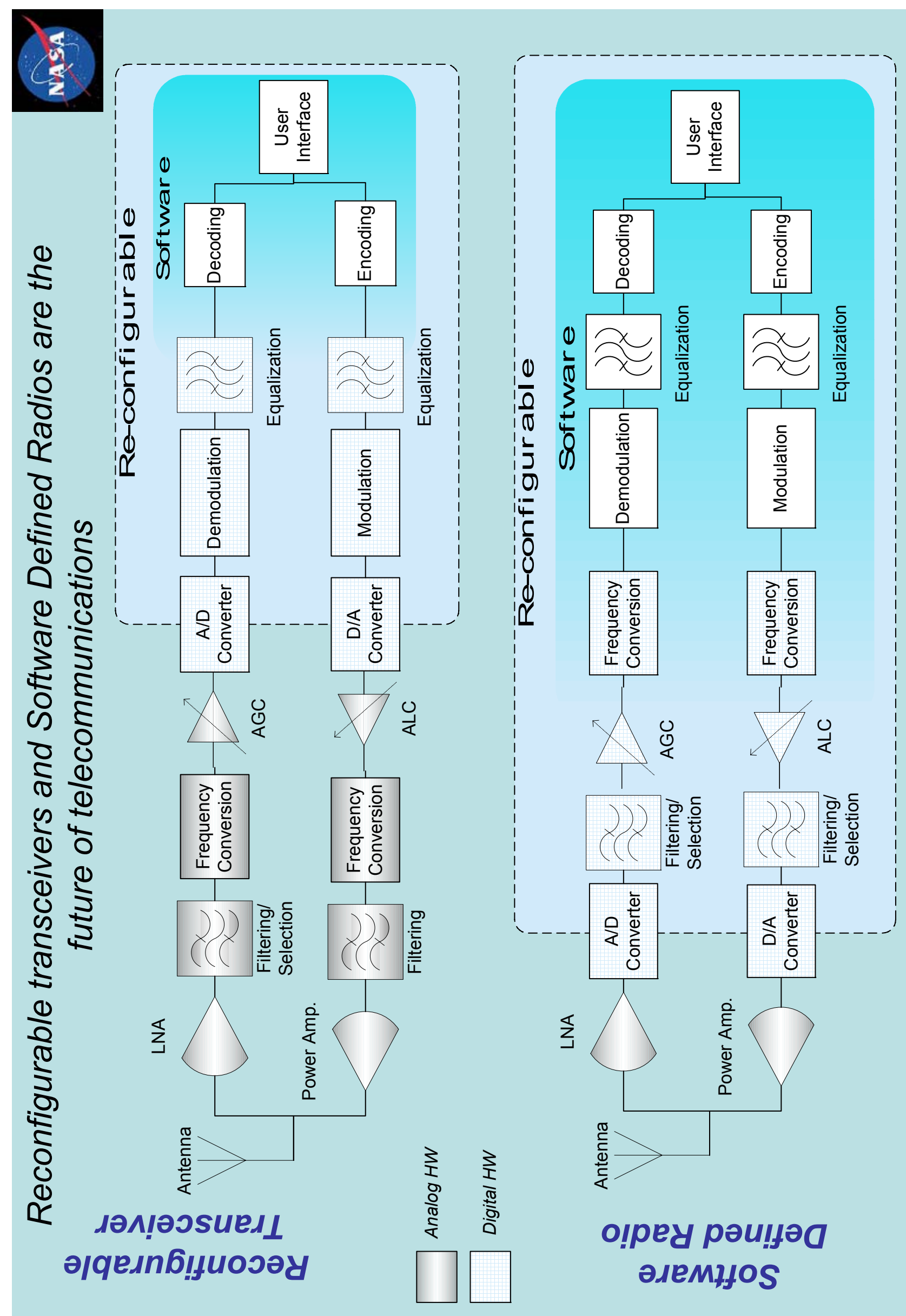




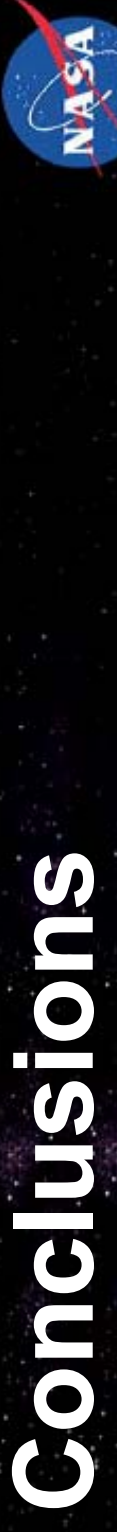

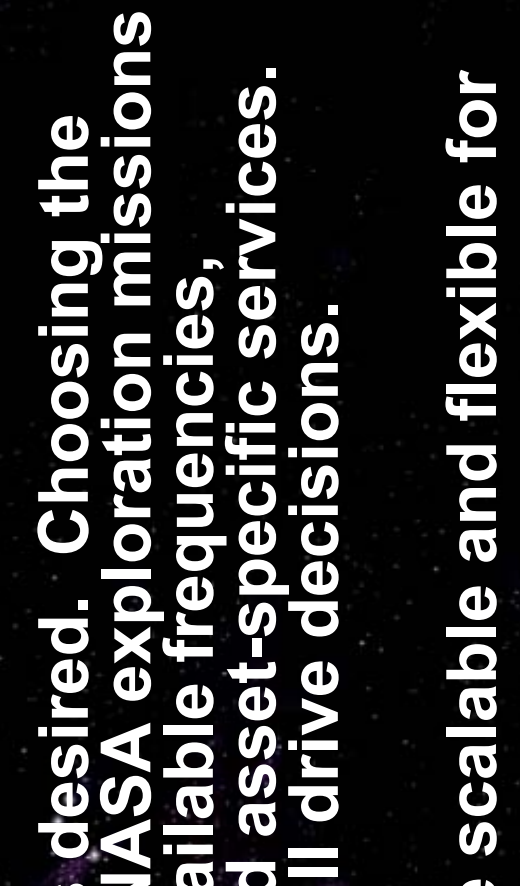

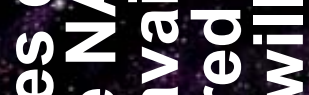

(1) (1) 1

o $=2 \%$

$4=100$

(1) 100

- 0 ह है

(1) 400

(1) - क म

$00 \div-U$

म 10 .

(b)

(1) 002

- (1)

$\theta+10$ (1)

a) 10030

(1)

(1)

$-\frac{1}{0} \omega$

0 क

- (1) 10 औ

人 62

$\rightarrow$ 운

m 0 이 $\frac{2}{4}$
$\frac{1}{0}$
$\frac{2}{x}$
4
$\frac{0}{10}$
$\frac{0}{0}$
$\frac{0}{00}$
$\frac{0}{00}$

(1)

Q.

을

53

01

क 3

$\theta$

(1) 10

이

$0 \frac{1}{0}$

0

co

룽

(4)

0 E

를

(1)

$+0$

$E$

(1)

20

$\geqslant 3$

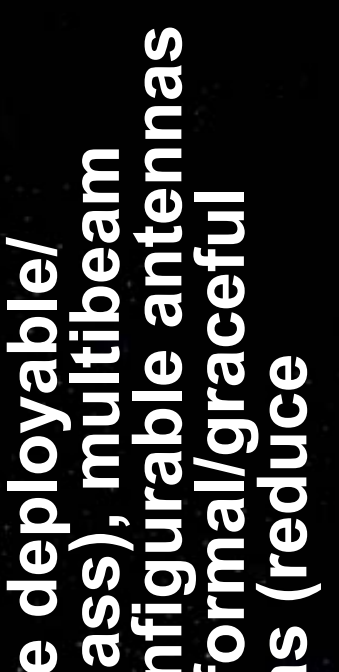

(1) 단

르를 to (1) (1) 0 406

- 2 -

n) $>>10$

(1) 00 (1)

- 음ㄷㄴ 는

잉 100

10 E⿱㇒日勺

(अ) 0 क

- $\frac{0}{\mu} \mathscr{C}$

อ 山 है

(3) 00

등 के

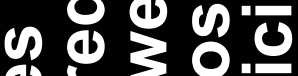

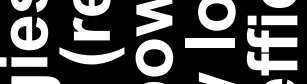

의 $0 \geqslant 4$

- 10 0 ( 0

- E 3 E

뤃ㅎㅇ

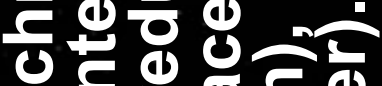

(1) 는 두

$40 \leq 00$

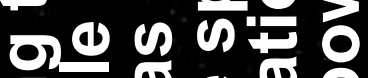

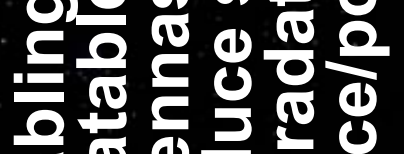

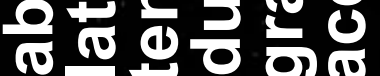

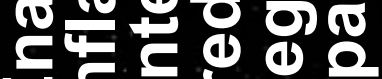

III단하
(6)

20

$\infty$

(1)

난

훌 (1)

훙

두을

로을

(1)

- 0 OL in

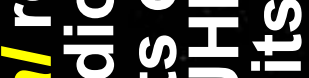

g $0+53$

(3) क

+ 164

\&1

(6) (1)

$\sigma^{\circ} \mathcal{1}$ 늘

$\geqslant \quad \dot{5} 0$

(1) (1)

- (1) क

- $\boldsymbol{\theta}$ (

उब क ह

क er

क क

(1) 0 \&

E $\omega$ \&

(b) (달

어 04

हक d 05

(1) $40>0$

(1) $30 \%$

5 후

항

10 $E \leqslant 0$

1 르은

르우을

E0.0 0

을

(a) 1050

() 0 () $E \mathcal{U}$

(0) 0 (1)

픈든 오을

45005

II) $\boldsymbol{C}$ है 